\title{
OS CUIDADOS DE SAÚDE DOS IDOSOS ENTRE AS LIMITAÇÕES ORÇAMENTÁRIAS E O DIREITO A UM MÍNIMO EXISTENCIAL ${ }^{1}$
}

Healthcare for the elderly: between the budget constraints and the right to an existential minimum

${ }^{1}$ Universidade Federal Fluminense. Niterói/RJ, Brasil.

Correspondência: Ricardo Perlingeiro. E-mail: perlingeiro@nupej.uff.br.

Recebido em: 19/11/2013. Revisado em: 09/01/2014. Aprovado em: 22/01/2014

\footnotetext{
${ }^{1}$ Adaptação do texto da conferência "Elderly healthcare in the face of budget constraint", ministrada no Health Law and Bioethics in an Aging Society, do $4^{\text {th }}$ International Seminar in Health Law and Bioethics, ocorrido na University of Reading, Reino Unido, em 25 de julho de 2013.
} 


\section{RESUMO}

$\mathrm{O}$ artigo tem como objetivo contextualizar os efeitos da realidade das finanças públicas no âmbito da criação (legislativa) e da justiciabilidade dos cuidados de saúde a idosos. Relaciona os aspectos econômicos aos conflitos originados no descompasso entre, de um lado, as pretensões e expectativas individuais e, de outro lado, os cuidados de saúde constantes de lei, de orçamento público e de procedimentos administrativos. Com fundamento no princípio do Estado de Direito, considera que a insuficiência de recursos financeiros e de recursos orçamentários públicos, apesar de implicar risco de limites à tutela jurisdicional dos direitos, não é necessariamente um óbice à exigibilidade dos cuidados de saúde e tampouco é impeditivo do exercício de qualquer outro direito subjetivo criado por lei. Ao final, é indicada a necessidade de maior compreensão da expressão um mínimo existencial (Existenzminimum) sobre cuidados de saúde a idosos, tendo como ponto de partida a realidade financeira dos Estados, de modo que estes se obriguem somente a prestações possíveis e que não gerem frustrações à sociedade.

\section{Palavras-chave}

Cuidados de Saúde de Idosos; Direito à Saúde; Direitos Humanos Internacionais; Mínimo Existencial (Existenzminimum); Orçamento Público.

\section{ABSTRACT}

The article contextualizes the effects of the realities of public finances on the (legislative) creation and judicial review of healthcare for the elderly. It establishes the relationship between economic factors and the conflicts arising out the claims and expectations of individuals, on the one hand, and the healthcare provided for by law, the public budget and administrative procedures. Based on the principle of the rule of law, the article considers that the lack of financial resources and budgetary resources, while threatening to impose limitations on the judicial protection of such rights, is not necessarily an obstacle to the enforceability of healthcare rights, nor does it prevent the exercise of any other subjective rights created by law. Finally, the article points out the need for a better understanding of the expression an existential minimum (Existenzminimum) in relation to healthcare for the elderly: the financial realities of each country must be taken into account, so that countries will make a commitment to only such services as are possible, without generating frustrations in society.

\section{Keywords}

Existential minimum (Existenzminimum); Healthcare for the Elderly; International $\mathrm{Hu}$ man Rights; Public Budget; Right to Health. 


\section{Introdução}

É bastante atual e frequentemente invocada a relação entre recursos orçamentários e direitos aos cuidados de saúde.

A propósito, em junho de 2013, o Brasil foi palco de manifestações populares como nunca antes visto. A base das reclamações à época - apartidárias - eram os direitos sociais e serviços públicos essenciais que não mais correspondem às expectativas da sociedade brasileira, notadamente os serviços públicos de saúde ${ }^{2}$. O governo federal, em defesa, alegava falta de recursos financeiros para atender àquela "explosiva" demanda.

Em se tratando de cuidado aos idosos, potencializam-se as dificuldades financeiras ${ }^{3}$, haja vista uma população constantemente crescente, com o aumento da expectativa de vida ${ }^{4}$ reclamando cuidados específicos em maior extensão e na proporção das evoluções tecnológicas ${ }^{5}$.

Vale lembrar a recente e polêmica declaração do Ministro das Finanças do Japão, país que ocupa a terceira posição na economia global, quando pediu aos

\footnotetext{
${ }^{2}$ ABRAHAM, Marcus. Direito é ferramenta fundamental de transformação social. Consultor Jurídico, São Paulo, 4 jul. 2013. Disponível em: <http://www.conjur.com.br/2013-jul-03/marcus-abraham-direito-ferramenta-fundamental-trasformacao-social\#autores>. Acesso em: 18 jul. 2013. Ver também reportagem publicada no jornal Folha de S. Paulo (Protestos pela saúde pública 'enterra' Dilma e ministros e critica governo. Folha de S. Paulo, São Paulo, 10 out. 2013. Disponível em: <http://www1.folha.uol.com.br/fsp/ cotidiano/119355-protesto-pela-saude-publica-enterra-dilma-e-ministros-e-critica-governo.shtml>. Acesso em: 10 out. 2013) e editorial publicado no jornal Valor Econômico (EDITORIAL. Manifestação por mais transporte, saúde e educação. Valor Econômico, São Paulo, 19 jun. 2013. Disponível em: <http://www.valor.com. br/politica/3167272>. Acesso em: 11 out. 2013).

${ }^{3}$ No Brasil, somente no ano de 2011, o Sistema Único de Saúde (SUS) gastou com medicamentos para pessoas idosas a importância aproximada de R \$ 701.391.688,66 (PORTAL da Saúde. Disponível em: <http:// www2.datasus.gov.br/DATASUS/index.php>. Acesso em: 11 out. 2013). Até o ano 2030, a previsão de gastos somam R\$ 63,5 bilhões (CANAL Saúde. Disponível em: <http://www.canal.fiocruz.br/destaque/index. php?id=859>. Acesso em: 11 out. 2013).

4“A população mundial está envelhecendo em uma velocidade constante, quase impressionante. 0 número total de pessoas com 60 anos de idade ou mais subiu de 200 milhões em 1950 para 400 milhões em 1982 e está projetada para atingir 600 milhões no ano de 2001 e 1,2 bilhão próximo ao ano de 2025, em cujo momento mais de $70 \%$ destes serão habitantes dos hoje chamados de países em desenvolvimento. O número de pessoas com 80 anos de idade ou mais cresceu e continua crescendo ainda mais drasticamente, indo de 13 milhões em 1950 para mais de 50 milhões hoje e com projeção de crescimento para 137 milhões em 2025. Este é o grupo populacional de crescimento mais rápido no mundo, projetado para aumentar em um fator de 10 entre 1950 e 2025, comparado com um fator de seis para o grupo de 60 anos da idade ou mais e um fator de pouco mais de três para a população total" (ORGANIZAÇÃO DAS NAÇÕES UNIDAS (ONU). Alto Comissariado das Nações Unidas para os Direitos Humanos. General comment 6: the economic, social and cultural rights of older persons. Genebra, 1995. Disponível em: <http://www.unhchr. ch/tbs/doc.nsf/0/482aOaced8049067c12563ed005acf9e>. Acesso em: 11 out. 2013). Conforme dados do IBGE, em 2003, existiam 16.022.231 idosos no Brasil, correspondendo a 9,3\% da população; em 2009, passaram a 21.736 .304 idosos, equivalente a $11,3 \%$ da população (INSTITUTO BRASILEIRO DE GEOGRAFIA E ESTATÍSTICA. Síntese de Indicadores Sociais. Disponível em: <http://www.ibge.gov.br/home/estatistica/ pesquisas/pesquisa_resultados.php?id_pesquisa=47>. Acesso em: 9 jan. 2014.

${ }^{5}$ PELÁEZ, Martha B; FERRER LUES, Marcela. Salud pública y los derechos humanos de los adultos mayores. Acta bioeth, Santiago, v. 7, n. 1, 2001. Disponível em: <http://dx.doi.org/10.4067/S1726569X2001000100011>. Acesso em: 11 out. 2013.
} 
idosos de seu país "que se apressassem em morrer" para aliviar a carga fiscal dos japoneses na assistência médica:

Ele reclamou das unidades de reanimação e dos tratamentos para prolongar a vida, dizendo que se sentiria mal se o ajudassem a prolongar sua vida, ainda mais sabendo que esse tratamento é pago pelo Estado. Em uma reunião do Conselho Nacional de Seguridade Social sobre as reformas que avançam para reduzir a carga fiscal, disse que o problema só será resolvido se os deixarmos morrerem, e depressa. "Falei sobre aquilo que creio pessoalmente, que é importante não prolongar a vida com tratamentos e passar os últimos dias de vida em paz." Quase um quarto da população do Japão, 128 milhões de habitantes, tem mais de 60 anos. Estima-se que a proporção aumente cerca de $40 \%$ nos próximos 50 anos, diz o jornal britânico. O aumento dos gastos sociais, principalmente para os idosos, representou um aumento de impostos sobre consumo de $10 \%$ no ano passado ${ }^{6}$.

Mas, afinal, é realmente o orçamento público um limite aos cuidados de saúde e, em especial, aos cuidados dos idosos?

\section{Segundo o Escritório do Alto Comissariado para os Direitos Humanos,}

Geralmente argumenta-se que os Estados que não podem prover esse direito não estão obrigados a adotar medidas para realizar esse direito ou podem postergar suas obrigações indefinidamente. Quando se considera o nível de implementação desse direito em um Estado particular, a disponibilidade de recursos em determinado momento e o contexto de desenvolvimento são levados em consideração. Todavia, nenhum Estado pode usar a justificativa de falta de recursos para uma incapacidade em respeitar suas obrigações. Os Estados devem garantir o direito à saúde no limite máximo de seus recursos disponíveis, mesmo que estes sejam escassos. Embora as medidas possam depender do contexto específico, todos os Estados devem atuar no sentido de cumprir suas obrigações em respeitar, proteger e cumprir?

Porém, a meu ver, aspectos diversos devem ser previamente considerados. São os cuidados de saúde direitos fundamentais? Direitos fundamentais a cuidados

\footnotetext{
6“EL MINISTRO de finanzas japonés, Taro Aso, sobre los ancianos: 'Que se den prisa y se mueran'”. 20MINUTOS.ES, Espanha, 22 jan. 2013. Disponível em: <http://www.20minutos.es/noticia/1707874>. Acesso em: 11 out. 2013. Abordagem semelhante em GANDRA, Alana. Mudanças demográficas aumentarão demandas por Previdência Social e Saúde. Agência Brasil, Brasília, 14 ago. 2013. Disponível em: <http://agenciabrasil.ebc.com.br/noticia/2013-08-14/mudancas-demograficas-aumentarao-demandas-por-previdencia-social-e-saude>. Acesso em: 11 out. 2013.

${ }^{7}$ ORGANIZAÇÃO DAS NAÇÕES UNIDAS (ONU). The Right to Health. Fact Sheet, n. 32. Disponível em: <http:// www.ohchr.org/Documents/Publications/Factsheet31.pdf>. Acesso em: 11 out. 2013.
} 
de saúde a idosos? Direitos fundamentais sociais absolutos? É importante distinguir os direitos a cuidados de saúde sob o ponto de vista substantivo e procedimental? Qual o impacto da realidade financeira do poder público nas políticas de saúde? De que forma podem se manifestar conflitos envolvendo cuidados de saúde em decorrência da insuficiência de recursos públicos? Como assegurar a execução forçada de sentenças ante a exaustão financeira das autoridades sanitárias? Em que consiste o mínimo existencial (Existenzminimum) afeto ao direito à saúde quanto aos seus aspectos procedimentais e substantivos? Haveria especificidades a um mínimo existencial quanto a cuidados de saúde a idosos?

\section{São os cuidados de saúde direitos fundamentais?}

\section{Fundamento internacional}

A comunidade internacional é contundente: "A saúde é um direito humano fundamental e indispensável para o exercício dos demais direitos humanos. Todo ser humano tem o direito de desfrutar do mais alto nível possível de saúde para que possa viver dignamente"s.

Com efeito, as ordens jurídicas internacional, regional e nacional geralmente trazem a ideia dos cuidados à saúde como um direito fundamental social.

No plano internacional, destaca-se o Pacto Internacional sobre Direitos Econômicos, Sociais e Culturais de 1966, em cujo artigo 12 está previsto que:

1. Os Estados Signatários do presente Pacto reconhecem o direito de toda pessoa de desfrutar o mais alto nível possível de saúde física e mental. 2. Entre as medidas que deverão ser adotadas pelos Estados Signatários do Pacto a fim de assegurar a plena efetividade deste direito, figurarão as necessárias para: a) A redução da mortalidade infantil e do índice de natimortos, bem como o desenvolvimento sadio das crianças; b) $\mathrm{O}$ aprimoramento em todos os seus aspectos da higiene do trabalho e do meio ambiente; c) A prevenção e o tratamento das doenças epidêmicas, endêmicas, profissionais e de outro tipo, e a luta contra elas; d) A criação de condições que garantam a todos assistência médica e serviços médicos em caso de doença'.

\footnotetext{
${ }^{8} \mathrm{ONU}$. Comitê de Direitos Econômicos, Sociais e Culturais. General comment 14: the right to the highest attainable standard of health (article 12 of the International Covenant on Economic, Social and Cultural Rights). Genebra, 2000. Disponivel em: <http://www.unhchr.ch/tbs/doc.nsf/(symbol)/E.C.12.2000.4.En>. Acesso em: 11 out. 2013.

${ }^{9}$ BRASIL. Decreto n ${ }^{\circ}$ 591, de 06 de julho de 1992. Pacto Internacional sobre Direitos Econômicos, Sociais e Culturais, adotado pela Assembleia Geral das Nações Unidas em 16 de dezembro de 1966 e ratificado pelo Brasil em 24 de janeiro de 1992. Disponível em: <http://www.planalto.gov.br/ccivil_03/decreto/1990-1994/D0591.htm>. Acesso em: 10 out. 2013. Outros tratados relacionados com o direito a saúde: Convenção no 29 Relativa ao Trabalho Forçado ou Obrigatório de 1930; Decreto n 41.721, de 25 de junho de 1957 (Brasil); Carta das Nações Unidas de 1945;
} 
O direito à saúde é também reconhecido na Convenção Internacional sobre a Eliminação de todas as formas de Discriminação Racial (CERD) de 1965 (artigo $5^{\circ}$, alínea e, inciso IV $)^{10}$, na Convenção sobre a Eliminação de todas as formas de Discriminação contra a Mulher (CEDAW) de 1979 (artigo 11.1, alínea f, e artigo 12) ${ }^{11}$ e na Convenção sobre os Direitos da Criança de 1989 (artigo 24, alínea d) ${ }^{12}$.

Diversas declarações e recomendações internacionais associam os cuidados de saúde a direitos fundamentais, valendo referência à Declaração Universal dos Direitos Humanos de 1948, no seu artigo 25, parágrafo $1^{\circ}$, em que:

Toda pessoa tem direito a um padrão de vida capaz de assegurar a si e a sua família saúde e bem-estar, inclusive alimentação, vestuário, habitação, cuidados médicos e os serviços sociais indispensáveis, o direito à segurança, em caso de desemprego, doença, invalidez, viuvez, velhice ou outros casos de perda dos meios de subsistência em circunstâncias fora de seu controle ${ }^{13}$.

A propósito, uma revisão da referida declaração demonstra que a maioria dos direitos e liberdades ali incluídos são componentes e determinantes de saúde ${ }^{14}$.

Convenção Para a Prevenção e a Sanção do Delito de Genocídio de 1948; Convenção Para a Supressão do Tráfico de Pessoas e da Exploração da Prostituição de Outrem de 1949; Convenção de Genebra para Melhorar a Execução dos Feridos e Doentes das Forças Armadas em Campanha de 1949; Convenção de Genebra para Aliviar o Destino dos Membros Feridos, Doentes e Náufragos das Forças Armadas no Mar de 1949; Convenção de Genebra Relativa ao Tratamento dos Prisioneiros de Guerra de 1949; Convenção de Genebra Relativa à Proteção das Pessoas Civis em Tempo de Guerra de 1949; Protocolo Adicional às Convenções de Genebra Relativas à Proteção das Vítimas dos Conflitos Armados Internacionais - Protocolo I, 1977; Protocolo Adicional às Convenções de Genebra Relativas à Proteção das Vítimas dos Conflitos Armados Não Internacionais - Protocolo II, 1977; Convenção Sobre o Estatuto de Refugiados de 1951; Convenção no 105 Sobre a Abolição do Trabalho Forçado de 1957; Convenção Sobre a Eliminação de Todas as Formas de Discriminação Racial de 1965; Pacto Internacional Sobre Direitos Civis e Políticos de 1966; Convenção Sobre a Eliminação de Todas as Formas de Discriminação Contra as Mulheres de 1979; Convenção Contra a Tortura e Outros Tratamentos Cruéis, Desumanos ou Degradantes de 1984; Convenção Sobre os Direitos da Criança de 1989; Convenção no 169 sobre Povos Indígenas e Tribais em Países Independentes de 1989; Convenção Internacional Sobre a Proteção dos Direitos de Todos os Trabalhadores Migrantes e dos Membros das Suas Familias de 1990; Convenção no 182 Sobre as Piores Formas de Trabalho Infantil e a Ação Imediata Para sua Eliminação de 1999; Convenção n 183 Sobre a Proteção da Maternidade de 2000.

${ }^{10}$ BRASIL. Decreto $n^{\circ}$ 65.810, de 08 de dezembro de 1969. Promulga a Convenção Internacional sobre a Eliminação de todas as formas de Discriminação Racial. Disponível em: <http://portal.mj.gov.br/sedh/ct/ legis_intern/conv_int_eliminacao_disc_racial.htm>. Acesso em: 11 out. 2013.

${ }^{11}$ BRASIL. Decreto n ${ }^{\circ} 4.316$, de 30 de julho de 2002. Promulga o Protocolo Facultativo à Convenção sobre a Eliminação de todas as formas de Discriminação contra a Mulher. Disponível em: <http://www.planalto. gov.br/ccivil_03/decreto/2002/D4316.htm>. Acesso em: 11 out. 2013.

${ }^{12}$ FUNDO DAS NAÇÕES UNIDAS PARA A INFÂNCIA (UNICEF). Convenção sobre os Direitos da Criança de 1989. Disponivel em: <http://www.unicef.org/brazil/pt/resources_10120.htm>. Acesso em: 11 out. 2013.

${ }^{13}$ ORGANIZAÇÃO DAS NAÇÕES UNIDAS (ONU). Declaração Universal dos Direitos Humanos foi proclamada pela Assembleia Geral das Nações Unidas em Paris, em 10 de Dezembro de 1948, através da Resolução 217 A (III) da Assembleia Geral. Disponível em: <http://unicrio.org.br/img/DeclU_D_HumanosVersolnternet.pdf>. Acesso em: 15 out. 2013. São declarações internacionais relacionadas com o direito à saúde: Declaração Universal dos Direitos Humanos de 1948; Declaração Sobre a Utilização do Progresso Científico e Tecnológico no Interesse da Paz e em Benefício da Humanidade de 1975; Declaração Sobre os Direitos das Pessoas com 
Merece igual destaque a Constituição da Organização Mundial da Saúde (OMS) de $1946^{15}$ indicando que o proveito do grau máximo de saúde que se pode conseguir é um dos direitos fundamentais de todo ser humano.

\section{Normas regionais de direitos humanos}

No cenário regional, confere-se ênfase aos sistemas de direitos humanos americano, europeu, africano e islâmico ${ }^{16}$.

A Declaração Americana de Direitos e Deveres do Homem de 1948, no artigo 11, prevê que "Toda pessoa tem direito a que sua saúde seja resguardada por medidas sanitárias e sociais relativas a alimentação, roupas, habitação e cuidados médicos correspondentes ao nível permitido pelos recursos públicos e os da coletividade"17.

Por sua vez, de acordo com a Convenção Interamericana de Direitos Humanos, pelo Protocolo Adicional de São Salvador de 1998:

1. Toda pessoa tem direito à saúde, entendida como o gozo do mais alto nível de bem-estar físico, mental e social; 2. A fim de tornar efetivo o direito à saúde, os Estados-Partes comprometem-se a reconhecer a saúde como bem público e, especialmente, a

Deficiência de 1975; Princípios de Ética Médica Aplicáveis à Função do Pessoal de Saúde, Principalmente Médicos, na Proteção de Presos e Detidos Contra a Tortura e Outros Tratamentos Cruéis, Desumanos ou Degradantes de 1982; Declaração Sobre o Direito ao Desenvolvimento de 1986; Princípios Para a Proteção de Doentes Mentais e a Melhoria dos Cuidados de Saúde Mental de 1991; Princípios das Nações Unidas Para os Idosos de 1991; Declaração Sobre os Direitos das Pessoas Pertencentes A Minorias Nacionais, Étnicas, Religiosas e Linguísticas de 1992; Normas Sobre a Equiparação de Oportunidades Para Pessoas com Deficiência de 1993; Declaração Sobre a Eliminação da Violência Contra as Mulheres de 1993; Declaração Universal Sobre o Genoma Humano e os Direitos Humanos de 1997; Declaração Sobre o Direito e a Responsabilidade dos Indivíduos, Grupos e Instituições Para Promover e Proteger os Direitos Humanos e as Liberdades Fundamentais Universalmente Reconhecidos de 1998; Princípios Orientadores Relativos aos Deslocados Internos de 1998; Plano de Ação Internacional Sobre o Envelhecimento de Madrid, 2002.

${ }^{14}$ PELÁEZ, Martha B; FERRER LUES, Marcela. op. cit.

${ }^{15} \mathrm{~A}$ Constituição foi adotada pela Conferência Sanitária Internacional, realizada em Nova lorque, de 19 de junho a 22 de julho de 1946, tendo sido subscrita pelos representantes de 61 Estados (Off. Rec. WId HIth Org.; Actes off. Org. mond. Santé, 2, 100), e entrou em vigor em 07 de abril de 1948. As reformas adotadas pela $26^{a}, 29^{a}, 39^{a}$ e 51 ${ }^{a}$ Assembleias Mundiais da Saúde (Resoluções WHA26.37, WHA29.38, WHA39.6 e WHA51.23), que entraram em vigor em 3 de fevereiro de 1977, em 20 de janeiro de 1984, em 11 de julho de 1994 e em 15 de setembro de 2005, respectivamente, foram incorporadas ao presente texto.

${ }^{16}$ Outros instrumentos regionais de direitos humanos com relação ao direito à saúde: Convenção Interamericana Para Prevenir e Punir a Tortura, de 1985; Protocolo à Convenção Americana Sobre Direitos Humanos Referente à Abolição da Pena de Morte, de 1990; Carta Africana Sobre os Direitos e Bem Estar da Criança, de 1990; Convenção Interamericana Para Prevenir, Punir e Erradicar a Violência Contra a Mulher - "Convenção de Belém do Pará", de 1994; Decreto n 1.973, de 01 de agosto de 1996 (Brasil); Carta Árabe dos Direitos Humanos de 1994; Convenção Para a Proteção dos Direitos Humanos e da Dignidade do Ser Humano Face às Aplicações da Biologia e da Medicina: Convenção Europeia dos Direitos do Homem e a Biomedicina de 1997; Convenção Interamericana Para a Eliminação de todas as Formas de Discriminação Contra as Pessoas Portadoras de Deficiência de 1999.

${ }^{17}$ CONFERÊNCIA INTERNACIONAL AMERICANA, IX, 1948, Bogotá. Declaração Americana dos Direitos e Deveres do Homem. Bogotá, OEA, 1948. Disponível em: <http://www.cidh.oas.org/basicos/portugues/b. Declaracao_Americana.htm>. Acesso em: 11 out. 2013. 
adotar as seguintes medidas para garantir esse direito: a. Atendimento primário de saúde, entendendo-se como tal a assistência médica essencial colocada ao alcance de todas as pessoas e famílias da comunidade; b. Extensão dos benefícios dos serviços de saúde a todas as pessoas sujeitas à jurisdição do Estado; c. Total imunização contra as principais doenças infecciosas; d. Prevenção e tratamento das doenças endêmicas, profissionais e de outra natureza; e. Educação da população sobre prevenção e tratamento dos problemas da saúde; e f. Satisfação das necessidades de saúde dos grupos de mais alto risco e que, por sua situação de pobreza, sejam mais vulneráveis ${ }^{18}$.

Na Europa, a Carta Social Europeia de 1996, em seu artigo 11, sobre o direito à proteção da saúde, assim dispõe:

Com vista a assegurar o exercício efetivo do direito à proteção da saúde, as Partes Contratantes comprometem-se a tomar, quer diretamente, quer em cooperação com organizações públicas e privadas, medidas apropriadas tendentes, nomeadamente: 1) A eliminar, na medida do possível, as causas de uma saúde deficiente; 2) A estabelecer serviços de consulta e de educação no que respeita à melhoria da saúde e ao desenvolvimento do sentido da responsabilidade individual em matéria de saúde; 3) A evitar, na medida do possível, as doenças epidémicas, endémicas e outras ${ }^{19}$.

No mesmo sentido, a Carta Europeia dos Direitos Fundamentais de 2007, no artigo 35, afirma que:

Todas as pessoas têm o direito de aceder à prevenção em matéria de saúde e de beneficiar de cuidados médicos, de acordo com as legislações e práticas nacionais. Na definição e execução de todas as políticas e ações da União é assegurado um elevado nível de proteção da saúde humana ${ }^{20}$.

E, a Carta Africana de Direitos Humanos e dos Povos de 1981, artigo 16, parágrafo $1^{\circ}$, diz que:

\footnotetext{
${ }^{18}$ OEA. Protocolo Adicional à Convenção Americana sobre Direitos Humanos em Matéria de Direitos Econômicos, sociais e culturais - "Protocolo de San Salvador" de 1988. Disponível em: <http://www.cidh.oas.org/ basicos/portugues/e.Protocolo_de_San_Salvador.htm>. Acesso em: 15 out. 2013.

${ }^{19}$ CONSELHO DA EUROPA. Carta Social Europeia. Estrasburgo, 1996. Disponível em: <http://www.dhnet.org. br/direitos/sip/euro/7.htm>. Acesso em: 11 out. 2013.

${ }^{20} \mathrm{~A}$ Carta dos Direitos Fundamentais da União Europeia foi “proclamada solenemente” pelo Parlamento Europeu, pelo Conselho da União Europeia e pela Comissão Europeia em 07 de dezembro de 2000. Uma versão adaptada da Carta foi proclamada em 12 de dezembro de 2007, em Estrasburgo, à frente da assinatura do Tratado de Lisboa. (EUR-LEX. Disponível em: <http://eur-lex.europa.eu/LexUriServ/LexUriServ.do?uri=0J:C:2007:303:0001:0016:pt:PDF>. Acesso em: 15 out. 2013).
} 
Toda pessoa tem direito ao gozo do melhor estado alcançável de saúde física e mental. $\$ 2^{\circ}$. Os Estados-Partes na presente Carta comprometem-se a tomar as medidas necessárias para proteger a saúde das suas populações e para assegurar-lhes assistência médica em caso de doença ${ }^{21}$.

Finalmente, a controvertida Declaração de Cairo sobre os Direitos Humanos no Islã, de 1993, artigo 17, alínea b, prevê que “Todas as pessoas terão direito aos cuidados médicos e sociais, e a todos os serviços públicos oferecidos pela Sociedade e o Estado dentro dos limites de seus recursos disponíveis"22.

\section{Constituições nacionais}

\section{Segundo Hogerzeil et al,}

A maioria dos países no mundo aderiu ou ratificou pelo menos um pacto ou tratado internacional ou regional que confirma o direito à saúde. Por exemplo, mais de 150 países se tornaram Estados partes para o Pacto Internacional sobre Direitos Econômicos, Sociais e Culturais - PIDESC, e 83 assinaram tratados regionais. Mais de 100 países incorporaram o direito à saúde em suas constituições nacionais ${ }^{23}$.

Em um panorama nacional não foram poucos os países que incorporaram em suas constituições o direito à saúde ${ }^{24}$.

A Constituição Federal brasileira, no artigo 196, dispõe que "A saúde é direito de todos e dever do Estado, garantido mediante políticas sociais e econômicas

\footnotetext{
${ }^{21}$ ORGANIZAÇÃO DA UNIDADE AFRICANA. Carta Africana de Direitos Humanos e dos Povos. Banjul, 1981. Disponivel em: <http://dhnet.org.br/direitos/sip/africa/banjul.htm>. Acesso em: 11 out. 2013

${ }^{22}$ ORGANIZAÇÃO DAS NAÇÕES UNIDAS (ONU). Assembleia Geral. Declaração de Cairo sobre os Direitos Humanos no Islã. Cairo, 1993. Disponível em: <http://www.arabhumanrights.org/publications/regional/islamic/cairo-declaration-islam-93e.pdf>. Acesso em: 15 out. 2013.

${ }^{23} \mathrm{HOGERZEIL}$ et al. Is access to essential medicines as part of the fulfilment of the right to health enforceable through the courts? The Lancet, v. 368, p. 305-311, 22 Jul. 2006. Disponivel em: <http://www.who. int/medicines/news/Lancet_EssMedHumanRight.pdf>. Acesso em: 21 out. 2013. Sobre os países que se tornaram Estados-Partes do PIDESC, ver o texto "Países signatários do Pacto Internacional sobre Direitos Econômicos, Sociais e Culturais" (ORGANIZAÇÃO DAS NAÇÕES UNIDAS (ONU). Pacto Internacional sobre Direitos Econômicos, Sociais e Culturais. Disponível em: <http://treaties.un.org/untc/Pages/ViewDetails. aspx?src=TREATY\&mtdsg_no=IV-3\&chapter=4\&lang=en\#2>. Acesso em: 11 out. 2013).

${ }^{24}$ Por exemplo, ver Constituição da Argentina, artigo 42, artigo 75, XXII; Constituição da Áustria, artigo 12 (1), 1, artigo10; Constituição do Chile, artigo 19, IX; Constituição da China, artigo 21, artigo 45, artigo 70, artigo 89, artigo 107, artigo 111, artigo 119; Constituição da Colômbia, artigo 49, artigo 50, artigo 64, artigo 300, X, artigo 366; Constituição da Costa Rica, artigo 46; Constituição de Cuba, artigo 43, artigo 44, artigo 50, artigo 103, artigo 104, artigo 105, “h”, artigo 106, “h”; Constituição da Finlândia, parágrafo 19; Constituição do Japão, artigo 25; Constituição do México, artigo 2, “b”, III, artigo 4, artigo 122; Constituição da Suiça, artigo 41, "b”, artigo 117, artigo 118, artigo 118b, artigo 119a; Constitução da Venezuela, artigo 83, artigo 84, artigo 85, artigo 86, artigo 122, artigo XXIII e XXIV, artigo 184, I.
} 
que visem à redução do risco de doença e de outros agravos e ao acesso universal e igualitário às ações e serviços para sua promoção, proteção e recuperação"25.

A Constituição de Portugal, no artigo 64, assim prescreve sobre os cuidados de saúde: "Todos têm direito à proteção da saúde e o dever de a defender e promover. $\mathrm{O}$ direito à proteção da saúde é realizado (...) através de um serviço nacional de saúde universal e geral e, tendo em conta as condições económicas e sociais dos cidadãos, tendencialmente gratuito" ${ }^{26}$.

A Constituição dos Países Baixos, no artigo 22, garante o direito a uma boa assistência. Todos aqueles que vivem e/ou trabalham nos Países Baixos devem ter o seguro de saúde básico, mas os demais terão ainda o direito aos cuidados básicos (embora estejam infringindo a legislação). Ele é monitorado pelo Healthcare Insurance Board ${ }^{27}$.

Uma das exceções fica por conta do Reino Unido e dos Estados Unidos, onde nem na Constituição nem na legislação há previsão de um direito à saúde ${ }^{28}$. É nítido que nesses sistemas, típicos de liberdades negativas, prevalece a noção de que os direitos fundamentais autorizam somente direitos procedimentais a políticas públicas de saúde ${ }^{29}$. O UK Human Rigths Act orienta as instituições vinculadas ao National Health Service (NHS), especialmente a partir dos princípios do direito à vida, à dignidade e à privacidade, porém não se extraindo deles a correspondência com o direito a medicamentos, serviços e produtos de saúde em quaisquer circunstâncias ${ }^{30}$. Nos Estados Unidos, os sistemas de saúde sempre foram predominantemente privados, com as exceções do Medicare e do Medicaid e, atualmente, do Affordable Care Act (ACA), que sofrem maior ingerência do poder público na assistência à saúde ${ }^{31}$.

\footnotetext{
${ }^{25}$ BRASIL. Constituição da República Federativa do Brasil de 1988. Disponível em: <https://www.planalto. gov.br/ccivil_03/constituicao/constituicao.htm>. Acesso em: 11 out. 2013.

${ }^{26}$ PORTUGAL. Constituição da República Portuguesa de 1976. Disponível em: <http://www.parlamento.pt/ Legislacao/Paginas/ConstituicaoRepublicaPortuguesa.aspx>. Acesso em: 11 out. 2013.

${ }^{27}$ HOGERZEIL et al. op. cit.

28“"The United States constitution does not provide for affirmative rights, however, several State constitutions include such provisions. Despite scholarly calls for State courts to enforce affirmative rights, State courts have not taken the opportunity to review State constitution welfare provisions". PASCAL, Elizabeth. Welfare Rights in State Constitutions. New York: Rutgers L.J., 2008. p. 863. Disponível em: <http://org.law.rutgers. edu/publications/lawjournal/issues/39_4/04PascalVol.39.4.r_1.pdf>. Acesso em: 15 out. 2013.

${ }^{29}$ Sobre direitos procedimentais (adjetivos) e direitos substantivos, ver o título V deste artigo. Anota Mark Tushnet haver uma tendência a não considerar justiciáveis os direitos sociais e econômicos [welfare rigths] afastados do núcleo das necessidades básicas, dos interesses fundamentais ou dos direitos substantivos fortes (TUSHNET, Mark. Social Welfare Rights and the Forms of Judicial Review. Texas Law Review, Austin, v. 82, n. 7, p. 1985-1919, 2004, apud TORRES, Ricardo Lobo. O direito ao mínimo existencial. Rio de Janeiro: Renovar, 2009. p. 133).

${ }^{30}$ EQUALITY AND HUMAN RIGHTS GROUP. Human rigths in healthcare: a short introduction. London: DH Publications Orderline, 2008. Disponível em: <http://www.bihr.org.uk/sites/default/files/Human\%20rights\%20 in\%20healthcare\%20-\%20short\%20introduction.pdf>. Acesso em: 11 out. 2013.

${ }^{31}$ SOUZA, Mariana Rodrigues Kelly. Princípio da universalidade: efeitos da reforma introduzida pelo Affordable Care Act. Niterói: UFF, 2012.
} 


\section{Direitos fundamentais a cuidados de saúde a idosos?}

O Protocolo Adicional à Convenção Americana sobre Direitos Humanos em matéria de Direitos Econômicos, Sociais e Culturais (Protocolo de San Salvador), no seu artigo 17, dispõe que toda pessoa tem direito à proteção especial na velhice e que os Estados devem progressivamente proporcionar-lhes assistência médica especializada. Ademais, vale assinalar que

Direitos humanos são, por definição, universais. Em virtude do alcance universal de todos os direitos, toda a gama de padrões e princípios de direitos humanos internacionalmente reconhecidos, como consta no cerne dos tratados de direitos humanos internacionais, também inclui e protege os idosos ${ }^{32}$.

O Pacto Sobre os Direitos Econômicos, Sociais e Culturais (PIDESC) e o Pacto Sobre Direitos Civis e Políticos (PIDCP) incluem disposições altamente relevantes para a proteção dos direitos humanos dos idosos, como os direitos à saúde, a um padrão adequado de vida, à proibição da tortura, à capacidade legal e à igualdade perante a lei ${ }^{33}$. Outros instrumentos, como as convenções CEDAW e a CERD, também contêm disposições que são aplicáveis aos idosos dentro de seus escopos relevantes. A Convenção Internacional de Proteção dos Direitos dos Trabalhadores Migrantes e Membros de suas famílias (ICMW), artigo 7º, inclui a "idade" na lista de considerações proibidas para discriminação ${ }^{34}$.

Dos Princípios das Nações Unidas em Favor das Pessoas Idosas, aprovados pela Assembleia Geral da Organização das Nações Unidas (ONU) ${ }^{35}$, destaco as seguintes diretrizes:

10. Idosos devem se beneficiar dos cuidados e da proteção da família e da comunidade em conformidade com o sistema de valores culturais de cada sociedade. 11. Idosos devem ter acesso aos cuidados de saúde que os ajudem a manter ou readquirir um nível ideal de bem-estar físico, mental e emocional e para prevenir ou retardar o surgimento de doenças. 12. Idosos devem ter acesso aos serviços sociais e jurídicos para melhorar sua autonomia, proteção e cuidados. 13. Idosos devem ser capazes de utilizar os meios adequados de assistência institucional que lhes forneça proteção, reabilitação e estímulo social e mental em uma atmosfera humana e segura. 14. Idosos devem ter a possibilidade de gozar os direitos humanos e as liberdades fundamentais

\footnotetext{
${ }^{32}$ ORGANIZAÇÃO DAS NAÇÕES UNIDAS (ONU). International Standards and Principles. Disponível em: <http:// www.ohchr.org/EN/Issues/OlderPersons/Pages/InternationalStandards.aspx>. Acesso em: 11 out. 2013.33ld. Ibid.

${ }^{34}$ Id. Ibid.

${ }^{35}$ ORGANIZAÇÃO DAS NAÇÕES UNIDAS (ONU). General Assembly. A/RES/46/91. Disponível em: <http:// www.un.org/documents/ga/res/46/a46r091.htm>. Acesso em: 15 out. 2013.
} 
quando residirem em qualquer abrigo, instituição de assistência ou tratamento, incluindo amplo respeito à sua dignidade, crenças, necessidades e privacidade e do direito de tomar decisões sobre seu próprio cuidado e a qualidade de suas vidas ${ }^{36}$.

O Plano de Ação Internacional Contra o Envelhecimento, resultado da II Assembleia Mundial do Envelhecimento realizada em Madri, 2002, promovida pela ONU, estabelece no seu artigo 14 que os participantes se comprometem a

proporcionar aos idosos, acesso universal e em condições de igualdade à assistência médica e aos serviços de saúde, tanto de saúde física como mental, e reconhecem que têm aumentado as necessidades de uma população que envelhece, por isso é preciso adotar novas políticas, especialmente em matéria de assistência e tratamento, promover meios de vida saudáveis e ambientes propícios ${ }^{37}$.

Também destaco o Escritório do Alto Comissariado para os Direitos Humanos da ONU, que desenvolveu documento de base intitulado Human rights of older persons: International Principles and Standards para a Reunião do Grupo de Especialistas ocorrida em 25 e 26 de maio de $2010^{38}$.

Convergindo para o entendimento segundo o qual os direitos dos idosos são direitos fundamentais, registrem-se ainda os seguintes documentos: The Committee on the Elimination of Discrimination against Women - CEDAW General Recommendation no. 27 on older women and protection of their human rights; The Committee on Economic, Social and Cultural Rights - CESCR, General Comment no. 6 on the economic, social and cultural rights of older persons; The CESCR, General Comment no. 19 on the right to social security ${ }^{39}$.

\section{Direitos fundamentais sociais absolutos?}

Os direitos fundamentais têm um âmbito de proteção amplo, apesar de se sujeitarem a restrições proporcionais e constitucionalmente justificáveis ${ }^{40}$. As restrições aos direitos fundamentais sociais ocorrem ante uma omissão ou uma atuação tímida do poder público que, ao mesmo tempo, devem ser proporcionais e estar lastreadas em fundamentos constitucionais ${ }^{41}$.

\footnotetext{
${ }^{36}$ ORGANIZAÇÃO DAS NAÇÕES UNIDAS (ONU). General Assembly. A/RES/46/91, cit.

${ }^{37}$ ORGANIZAÇÃO DAS NAÇÕESS UNIDAS (ONU). Plano de ação internacional contra o envelhecimento, 2002. Organização das Nações Unidas; tradução de Arlene Santos. Brasília: Secretaria Especial dos Direitos Humanos, 2003. 49 p. (Série Institucional em Direitos Humanos; v. 1). Disponível em: <http://www.saudeidoso.icict.fiocruz.br/ pdf/PlanodeAcao\%2OInternacionalpara\%20oEnvelhecimentodaONU.pdf>. Acesso em: 9 jan. 2014.

${ }^{38}$ ORGANIZAÇÃO DAS NAÇÕES UNIDAS (ONU). Human rights of older persons: International human rights principles and standards. Disponivel em: <http://www.ohchr.org/Documents/Issues/OlderPersns/OHCHRBackgroudpaper2011.pdf>. Acesso em: 9 jun. 2014.

${ }^{39}$ Id. Ibid.

${ }^{40}$ SILVA, Virgílio Afonso da. Direitos fundamentais. 2. ed. São Paulo: Malheiros Ed., 2011. p. 74-75, 154

${ }^{41}$ Id. Ibid., p. 77-78.
} 
O conteúdo essencial de um direito fundamental social, atrelado ao princípio da dignidade da pessoa, confunde-se com o mínimo existencial (Existenzmini$m u m)^{42}$, cujo âmbito de proteção é corolário lógico da aplicação da regra da proporcionalidade no caso concreto (este não se limitando necessariamente a situações individuais, mas coletivas também $)^{43}$,

Segundo Alexy, "restrições que respeitem a máxima da proporcionalidade não violam a garantia do conteúdo essencial ainda que, no caso concreto, nada restar do direito fundamental" e, no caso específico do direito ao mínimo existencial, em direitos sociais, "as ponderações [possam] conduzir, em circunstâncias distintas, a direitos definitivos distintos" 4 .

Partindo de uma premissa diversa, a de que os direitos fundamentais contêm um suporte fático reduzido e, com isso, o mínimo teria um caráter absoluto ${ }^{45} \mathrm{em}$ face da dignidade humana, pouca ou nenhuma discricionariedade pode ser conferida ao legislador infraconstitucional.

Contudo, tarefa nem sempre fácil é a própria compreensão do mínimo. A propósito, Pieroth e Schlink observam que

A questão de saber até onde vai a responsabilidade do Estado social, sob o aspecto da dignidade da pessoa humana, está especialmente vinculada aos padrões e também à riqueza de uma sociedade; se a jurisprudência fala da manutenção do mínimo existencial, este critério está dependente do tempo e da situação ${ }^{46}$.

De acordo com um recente julgado do Tribunal Constitucional alemão de $2010^{47}$, os cidadãos têm direito aos pressupostos materiais indispensáveis à sua existência física (alimentação, vestuário, artigos domésticos, habitação,

\footnotetext{
${ }^{42}$ Segundo Celine Fercot, o direito ao mínimo pode ter fundamentos diferenciados: na dignidade da pessoa humana, de forma autônoma, como em Israel, e vinculada ao Estado Social, a exemplo da Alemanha e da Colômbia. Menciona, ainda, o direito ao mínimo decorrendo diretamente do direito à vida, como na Índia, ou decorrendo do direito à vida e à dignidade associados, como no direito sul-africano. (FERCOT, Celine. Le juge et le droit au minimum. Les ambiguïtes du droit à des conditions minimales d'existence en droit comparé. In: ROMAN, Diane (Org.). Droits des pauvres, pauvres droits? Paris: Centre de Recherches sur les droits fondamentaux (CREDOF), Université Paris Ouest Nanterre la Défense, 2010, p. 239-243. Disponível em: <http://www.droits-sociaux.u-paris10.fr/assets/files/rapport_final/Justiciabilité_droits_sociaux_rapport_final.pdf $>$. Acesso em: 18 jan. 2013).

${ }^{43} \mathrm{Na}$ reserva do possível se manifesta o princípio da proporcionalidade no âmbito do Estado orçamentário. (KIRCHOF, F. Umfassende Staatsgewalt mit begrenzten Mitteln. In: ISENSSE, J.; KIRCHHOF, P. Handbuch des Staatsrecht, § 99. Heidelberg, 2007. v. 5). SILVA, Virgílio Afonso da. op. cit., p. 197, 204; ALEXY, Robert. Teoria dos direitos fundamentais. Tradução de Virgílio Afonso da Silva. São Paulo: Malheiros Ed., 2008. p. 297-298. ${ }^{44}$ ALEXY, Robert. op. cit., p. 297, 513.

${ }^{45}$ Anota ALEXY (op. cit., p. 298-301) que o Tribunal Constitucional Federal alemão tem precedentes no sentido da natureza absoluta do núcleo essencial.

${ }^{46}$ PIEROTH, Bodo; SCHLINK, Bernhard. Direitos fundamentais. São Paulo: Saraiva, 2012. p. 172.

${ }^{47}$ ALEMANHA. Tribunal Constitucional Federal (BVerfG). 1 BvL 1/09 - 1 BvL 3/09 - 1 BvL 4/09. j. 9 fev. 2010. Disponível em: <http://www.bundesverfassungsgericht.de/entscheidungen/Is20100209_1bvl000109. html>. Acesso em: 23 abr. 2013.
} 
aquecimento, saneamento e saúde) e a um mínimo de participação na vida social, cultural e política, porque o ser humano, como pessoa, está necessariamente inserido nas relações sociais ${ }^{48}$.

Segundo aquela mesma decisão judicial, o mínimo deve corresponder ao nível de desenvolvimento da comunidade e das condições de vida existentes, sujeitos à atualização contínua e aqui residindo a única margem de manobra da lei, o que, ainda assim, não afasta do poder público o dever de indicar de modo transparente e compreensível as demais despesas públicas, e também de fundá-las em um método de cálculo confiável e consistente ${ }^{49}$.

\section{Os direitos a cuidados de saúde substantivos e procedimentais}

Como se sabe, o direito subjetivo pode ser entendido sob os aspectos substantivo e adjetivo, à medida que este último destina-se a garantias de realização prática daquele $e^{50}$. É atualmente indiscutível que os meios necessários à concretização de um direito substantivo integram de forma autônoma a estrutura de um próprio direito subjetivo, isto é, um direito adjetivo (procedimental).

No plano dos direitos fundamentais, também se conhece essa abordagem, em que a conexão entre direitos fundamentais, organização e procedimento é conhecida como o due process dos direitos fundamentais (relacionado com a face procedimental das liberdades constitucionais) e frequentemente considerada um, ou mesmo o único meio para produção de resultados em conformidade com os direitos fundamentais ${ }^{51}$.

No mesmo contexto, inserem-se as políticas públicas, que designam de forma geral a "coordenação dos meios à disposição do Estado, harmonizando as atividades estatais e privadas para a realização de objetivos socialmente relevantes e politicamente determinados" 52 e, segundo Javier Barnes, compreendem a terceira

\footnotetext{
${ }^{48}$ Karl-Peter Sommermann indica que anteriormente à decisão do Tribunal Constitucional Federal (BVerfG 9 fev. 2010) "recurrentes conseguían en varios casos una extensión de prestaciones basándose en una violación del principio de igualdad, alegando que el grupo al que pertenecen consigue menos prestanciones que otro, sin que haya justificación por el trato desigual". Contudo, agora se extrai diretamente da Constituição o direito ao mínimo, apesar da base da prestação continuar sendo uma lei, que, ante a sua ausência, caracterizará uma omissão constitucional. (SOMMERMANN, Karl-Peter. Soziale Rechte in Stufen: Überwindung einer alten Debatte? In: CALLIESS, Christian; KAHL, Wolfgang; SCHMALENBACH, Kirsten (Orgs.). Rechtsstaatlichkeit, Freiheit und soziale Rechte in der Europäischen Union, 2013.)

${ }^{49}$ ALEMANHA. Tribunal Constitucional Federal (BVerfG). 1 BvL 1/09 - 1 BvL 3/09 - 1 BvL 4/09. j. 9 fev. 2010, cit.

${ }^{50}$ FALZEA, Angelo. Introduzione alle scienze giurdiiche: il concetto del diritto, 6 ed. Milano: Giuffrè, 2008. p. 455.

${ }^{51}$ HÄBERLE, Peter. Grundrechte im Leistungsstaat, VVDStRL 30, 1972, p. 81, apud ALEXY, Robert. op. cit., p. 470; HESSE, 1978, p. 434-435, apud ALEXY, Robert. op. cit., p. 470.

${ }^{52}$ BARCELLOS, Ana Paula de. A construção de um mínimo existencial em matéria de prestações de saúde. In: SOUZA NETO, Cláudio Pereira; SARMENTO, Daniel (Orgs.). Direitos sociais: fundamentos, judicialização e direitos sociais em espécie. Rio de Janeiro: Lumen Juris, 2008. p. 112.
} 
geração dos procedimentos administrativos, ao lado de atos e normas elaborados em torno das novas formas de governança ${ }^{53}$.

Quanto ao papel condicionante do exercício prévio de um direito adjetivo para satisfazer um direito substantivo em face da administração, Hans Wolff et al assinalam que "os direitos materiais têm de penetrar no procedimento e que os direitos fundamentais devem ser realizados através do procedimento" ${ }^{54}$.

Ademais, é sob essa orientação que o código modelo de jurisdição administrativa para Euro-América, no seu artigo 33, dispõe que, "sem prejuízo da obtenção de medidas cautelares, não se pode requerer uma condenação de fazer, dar ou pagar uma quantia sem haver sido previamente solicitada à Administração Pública competente" ${ }^{55}$, o que não se confunde com o recurso administrativo prévio à intervenção jurisdicional - uma faculdade do interessado, o qual, entretanto, mesmo após iniciar-se, tampouco impede as medidas jurisdicionais de urgência em favor do próprio interessado ${ }^{56}$.

A imperatividade que se espera de um direito (dever) procedimental prévio, inclusive associado a políticas públicas legislativas e orçamentárias, enquadra-se em especial a direitos sociais sujeitos à discricionariedade política do legislador, principalmente as pretensões que extrapolam um mínimo existencial, e nas quais

\footnotetext{
${ }^{53}$ BARNES, Javier. Tres generaciones de procedimiento administrativo. In: ABERASTURY, Pedro; BLANKE, Hermann-Josef (Orgs.). Tendencias actuales del procedimiento administrativo en Latinoamérica y Europa. Buenos Aires: Fundación Konrad Adenauer, 2012. p. 119-164.

${ }^{54}$ WOLF, Hans J.; BACHOF, Otto; STOBER, Rolf. Direito administrativo. Tradução de Antônio F. de Souza. Lisboa: Fundação Calouste Gulbenkian, 2006. v. 1, p. 255, 490. Também ver MAURER, Hartmut. Derecho administrativo alemán. Cidade do México: UNAM, 2012. p. 479.

${ }^{5}$ UNIVERSIDADE FEDERAL FLUMINENSE, Código modelo de jurisdição administrativa para Euro-América, Niterói, 2010. Texto elaborado durante os três seminários de pesquisa euro-americano euro-americana "Código modelo de jurisdição administrativa", organizados pelo Grupo de Pesquisa "Efetividade da Jurisdição" na Universidade Federal Fluminense, Niterói, e na Universidade Alemã de Ciências da Administração Pública, Speyer, entre os anos 2008 e 2010, e aprovado no III Seminário que ocorreu em setembro de 2010, em Niterói. Participaram da elaboração: Pedro Aberastury, Hermann-Josef Blanke, Gabriele Bottino, David Capitant, Jesús María Casal, Diana-Urania Galleta, Ricardo Garcia Macho, Leonardo Greco, Lorena Ossio, Gilles Pellissier, Ricardo Perlingeiro e Karl-Peter Sommermann. Com a mesma orientação, a Súmula 2 do Superior Tribunal de Justiça (Não cabe o habeas data se não houve recusa de informações por parte da autoridade administrativa). A respeito do prévio procedimento administrativo como condição para a tutela judicial em matéria de benefício social, há controvérsias nos tribunais brasileiros, encontrando-se o tema atualmente pendente de uniformização perante o Supremo Tribunal Federal (BRASIL. Supremo Tribunal Federal. Plenário. Repercussão Geral no Recurso Extraordinário 631.240/MG. Rel. Min. Joaquim Barbosa. Disponivel em: <www.stf.jus.br>. Acesso em: 18 jun. 2013).

${ }^{56}$ Sobre a diferença entre procedimento administrativo prévio e recurso administrativo prévio, ver GORDILLO, Augustín. Tratado de derecho administrativo: el procedimiento administrativo. 7. ed. México: Porruá, 2004. t. 4, p. 106-107, 116; BREWER-CARÍAS, Allan R. Principios del procedimento administrativo en América Latina. Bogotá: LEGIS, 2003. p. 287,294. Sobre o caráter facultativo do recurso administrativo, ver o artigo 53 do Código Modelo de Processos Administrativos - Judicial e Extrajudicial - para Ibero-América, e o artigo 32 do Código modelo de jurisdição administrativa para Euro-América. Em sentido contrário, quanto ao recurso administrativo prévio, dispõe o artigo 217, parágrafo $1^{\circ}$ da Constituição brasileira que os tribunais só admitirão demandas judiciais relativas à disciplina e às competições desportivas após esgotarem-se as instâncias perante a autoridade administrativa correspondente. Também parece ser esse o entendimento de Leonardo Greco (GRECO, Leonardo. Instituições de processo civil. Rio de Janeiro: Forense. 2009. v. 1, p. 233).
} 
o direito a uma prestação estatal depende da prévia oportunidade de que todos os interessados dele tenham chances de participar ${ }^{57}$.

Nesse contexto, é através do procedimento administrativo que se buscam critérios objetivos, claros, controláveis, que priorizem os produtos e serviços a idosos dentre os recursos destinados à saúde, e se orientem sob primazia de um mínimo existencial em matéria de idosos.

Com efeito, as pretensões judiciais para a entrega de medicamentos ou prestação de serviços de saúde (direitos substantivos) são suportadas naturalmente pelos recursos financeiros afetados à rubrica orçamentária inerente aos próprios serviços públicos de saúde em geral (direitos procedimentais). Porém, como uma medida jurisdicional dessa natureza atinge uma diversidade de usuários daquele mesmo serviço público, significa que a satisfação de uma pretensão judicial deve ser condicionada a uma reestruturação prévia da autoridade administrativa quanto à distribuição dos recursos disponíveis às sucessivas pretensões que lhe são apresentadas extrajudicialmente.

É, por tal razão, imprescindível que a justiciabilidade dos direitos aos cuidados de saúde ensejem da mesma forma a judicialização prévia ou simultânea do direito procedimental, isto é, que não apenas a pretensão ao medicamento, ao produto ou ao serviço de saúde (direito substantivo) seja jurisdicionalizada, mas principalmente a pretensão ao procedimento administrativo (direito procedimental), para obter o produto ou serviço de saúde, propiciando, assim, uma dimensão maior e potencial à tutela jurisdicional, de modo a ser capaz de assegurar a igualdade entre todos os usuários do serviço público de saúde.

Se por algum motivo não se judicializa o procedimento administrativo (direito procedimental), a satisfação da pretensão judicial material (direito substantivo) deve ser suportada por outros recursos financeiros, sem relação com os serviços públicos de saúde, isso porque a tutela jurisdicional em favor de uma pretensão individual esbarra na necessidade de continuidade de serviços públicos essenciais. Não é admissível que o direito subjetivo de um demandante seja exercido mediante o sacrifício de um serviço público essencial a outrem ${ }^{58}$.

\section{0 impacto da realidade financeira do poder público nas políticas de saúde: legislação, orçamento público, gestão da saúde pública}

Ainda que os direitos substantivos estejam subordinados aos direitos procedimentais, este fato, por si só, não esvazia os conflitos que envolvem a exigibilidade e

\footnotetext{
${ }^{57}$ Sobre os direitos de participação, PIEROTH, Bodo; SCHLINK, Bernhard. op. cit., p. 73 ; WOLF, Hans J.; BACHOF, Otto; STOBER, Rolf. op. cit., p. 488-489.

${ }^{58}$ Sobre a execução forçada de decisões judiciais contra autoridades administrativas sanitárias, ver o título VII deste artigo.
} 
justiciabilidade dos direitos aos cuidados de saúde, especialmente os conflitos com fundamento na insuficiência de recursos financeiros do poder público.

É claramente possível imaginar que uma autoridade administrativa, apesar de cumprir adequadamente as normas procedimentais, não tenha recursos financeiros suficientes para atender às múltiplas e inesperadas demandas.

De fato, a realidade financeira do poder público influi em três níveis distintos dos direitos à saúde: (a) ante o legislador, para decidir quais direitos serão adotados, considerando, de um lado, um mínimo existencial e, de outro lado, a discricionariedade política e proporcional para estender o direito a prestações além de um mínimo; (b) ante o orçamento público, para decidir quanto e como se gastará com um mínimo existencial e também com os demais cuidados à saúde implantados pelo legislador, considerando, de um lado, os recursos financeiros essenciais para assegurar o exercício efetivo dos direitos aos cuidados existentes e, de outro lado, a discricionariedade política e proporcional para estender recursos financeiros a prestações periféricas a esses direitos aos cuidados de saúde; (c) ante a autoridade administrativa, para decidir de que forma e quais prestações de saúde serão ofertadas, considerando, de um lado, vinculado aos recursos orçamentários existentes, o direito a um mínimo existencial e os demais cuidados à saúde implantados pelo legislador e, de outro lado, uma atuação discricionária administrativa proporcional capaz de racionalizar concretamente o uso dos recursos financeiros necessários ao exercício desses direitos de saúde.

\section{Os conflitos envolvendo cuidados de saúde decorrentes da insuficiência de recursos financeiros públicos}

Em consequência, sob o ponto de vista financeiro, os conflitos envolvendo os direitos aos cuidados de saúde que deságuam nos tribunais podem ser examinados sob perspectivas distintas.

Primeiro, com referência à constituição (existência) do próprio direito aos cuidados de saúde, diante de um descompasso entre uma pretensão individual e o direito aos cuidados efetivamente implantado pelo legislador, em um típico conflito de jurisdição constitucional, em que os recursos financeiros servirão, de um lado, para identificar o mínimo existencial e, de outro lado, para controlar a discricionariedade do legislador sobre o alcance das prestações de saúde, além de um mínimo, a serem por ele instituídas.

A propósito, em face de um mínimo existencial, o direito aos cuidados de saúde nasce com a Constituição, atrelado à essência de um direito fundamental à saúde ou coincidente com o princípio da dignidade humana ${ }^{59}$. Nesse caso, a margem de discricionariedade do legislador é zero e, consequentemente,

\footnotetext{
${ }^{59}$ Sobre os fundamentos do direito ao mínimo, ver nota 44 deste artigo.
} 
a exigibilidade e a justiciabilidade do direito aos cuidados de saúde são automáti$\cos ^{60}$, não dependem do legislador, cuja omissão é considerada inconstitucional e passível de controle jurisdicional ${ }^{61}$.

A outra perspectiva dos conflitos, envolvendo cuidados à saúde e finanças públicas, está relacionada não com a criação dos direitos aos cuidados à saúde, mas sim, partindo da premissa de que esses direitos já existem, com a sua exigibilidade e justiciabilidade em si.

Nesse particular, o conflito pode ter duas origens distintas, uma no orçamento público, outra no comportamento da própria autoridade administrativa.

No primeiro caso, se um mínimo existencial e os direitos aos cuidados de saúde em geral, criados por lei, não estiverem suficientemente lastreados no orçamento, o que por si só representa uma ofensa ao princípio do Estado de Direito ${ }^{62}$, abre-se a oportunidade ao reconhecimento judicial de demandas individuais e à execução forçada das sentenças.

O orçamento público é determinante como garantia de um sistema jurídico democrático na distribuição de benefícios sociais, somente em face de direitos que, apesar de se originarem na Constituição, dependem de lei para serem exigíveis. Contudo, o orçamento público não é capaz de esvaziar o direito a um mínimo existencial ou a direitos sociais já instituídos por lei ${ }^{63}$.

No segundo caso, o conflito decorre do comportamento da autoridade administrativa, que, apesar da existência em lei de recursos orçamentários, alega

${ }^{60}$ Frente ao mínimo existencial, o direito social é um dever do poder público vinculado originariamente à Constituição e desde logo judicialmente exigível (ALEXY, Robert. op. cit., p. 502, 512-513). No mesmo sentido: MENDES, Gilmar Ferreira; COELHO, Inocêncio Mártires; BRANCO, Paulo Gustavo Gonet. Curso de direito constitucional. São Paulo: Saraiva, 2007. p. 253. Para a jurisprudência da Corte Constitucional italiana o núcleo mínimo é "ineliminável” do direito à prestação (CILIONE, Giampiero. Diritto sanitario. Santarcangelo di Romagna: Maggioli Editore, 2005. p. 21).

${ }^{61}$ Sommermann admite que em casos extremos seria possível invocar o direito a um mínimo existencial, diretamente da Constituição, sem valer-se de uma jurisdição constitucional. Segundo ele, "cuando huvo todavía huecos en la legislación social y pocos recursos - lo que fue el caso particularmente en los años 50 del siglo pasado, cuando habían venido muchos refugiados a Alemania occidental donde muchas ciudades sufrían todavía de las destrucciones de la guerra - las autoridades públicas y los tribunales ordinarios aplicaban la cláusula general de policía para garantizar un mínimo existencial. Así, por ejemplo, se obligaba a familias de alojar personas sin vivienda en su casa o apartamento. Es decir, si falta una legislación social suficiente, hay posibilidades de ayuda directa através de las cláusulas generales, interpretatdas a la luz de la exigencia constitucional de asegurar el mínimo existencial". (SOMMERMANN, Karl-Peter. op. cit.).

62"A country's difficult financial situation does NOT absolve it from having to take action to realize the right to health" (ORGANIZAÇÃO DAS NAÇÕES UNIDAS (ONU). The Right to Health. Fact Sheet, n. 32, cit.).

${ }^{63}$ Alexy afirma que "A força do princípio da competência orçamentária do legislador não é ilimitada. Ele não é um principio absoluto. Direitos individuais podem ter peso maior que razões político-financeiras" (Teoria dos direitos fundamentais, cit., p. 512-513). Para Alexy, "mesmo os direitos fundamentais sociais mínimos têm, especialmente quando são muitos que deles necessitam, enormes efeitos financeiros. Mas isso, isoladamente considerado, não justifica uma conclusão contrária à sua existência". (op. cit., p. 512). 0 Tribunal Constitucional Federal alemão decidiu que aspectos econômicos não podem ser considerados para negar aos segurados o reembolso de despesas com novos tratamentos médicos necessários à cura de enfermidade com risco de vida. (ALEMANHA. Tribunal Constitucional Federal (BVerfG). 1 BvR 347/98, Absatz-Nr. (1 - 69). j. 6 dez. 2005. Disponível em: <http://www.bverfg.de/entscheidungen/rs20051206_1bvr034798.html>. Acesso em: 17 jan. 2013. 
não ter efetivamente recursos financeiros para atender às demandas de cuidados à saúde. Nessas situações, afronta-se igualmente o Estado de Direito e, então, admite-se a tutela judicial individual contra as autoridades públicas.

\section{A execução forçada de decisões judiciais e suas limitações diante da exaustão financeira das autoridades públicas de saúde}

Então, sob o ponto de vista teórico, a falta de recursos orçamentários não é um obstáculo à exigibilidade e justiciabilidade dos direitos aos cuidados de saúde ${ }^{64}$.

Porém, encontrando-se as autoridades administrativas atreladas a uma legalidade estrita, desprovida de meios para per si interpretar e aplicar diretamente a Constituição, a falta de orçamento servirá de justificativa para não cumprir as prestações sociais e levará inevitavelmente a uma judicialização, em cuja execução, entretanto, a expropriação de bens e de finanças públicas, em princípio, subordina-se à inexistência de ofensa a interesse público ou a serviço essencial, o que, portanto, nem sempre corresponde a uma jurisdição plena ${ }^{65}$.

Por exemplo, uma demanda judicial individual destinada a internação hospitalar, para o tratamento de uma enfermidade curável, junto ao sistema público de saúde, que não detém orçamento suficiente para suprir a ausência de leitos ou de médicos. Lamentavelmente, um exemplo muito comum nos tribunais brasileiros.

É inquestionável que esse direito deve ser judicialmente reconhecido; por outro lado, contudo, na execução da sentença não faria sentido sacrificar alguém que estivesse internado, com as mesmas necessidades, para atender ao demandante. A execução deve ser por ato de terceiros, como a contratação de leitos privados, porém desde que haja recursos públicos financeiros para tanto não afetados a outros serviços essenciais.

A propósito, em uma execução forçada de decisões judiciais sobre direito à saúde contra autoridades administrativas, expropria-se judicialmente o patrimônio

\footnotetext{
${ }^{64}$ Sobre a execução de decisões judiciciais contra autoridades administrativas, ver em geral CONGRÈS DE L'ASSOCIATION INTERNATIONALE DES HAUTES JURIDICTIONS ADMINISTRATIVES, 8, 2004, Madrid. L'exécution des decisions des jurisdictions administratives. Disponivel em: <http://www.aihja.org/images/ users/1/files/2004_CCongres_de_Madrid__Rapport_VIII_congres_VIII_vf.pdf?PHPSESSID=f83dg63dqj61vokoep4kk44fu1>. Acesso em: 15 out. 2013.65N̄o Brasil, admite-se em geral a execução forçada de decisões judiciais contra autoridades administrativas, exceto quando contrárias ao interesse público (Lei 12.016/2009, artigo 15; Lei 8.437/1992, artigo 4 , caput e parágrafo 1º Lei n 9.494/1997, artigo 1%). Em especial às execuções de decisões condenatórias de pagamento de dinheiro, não cabe execução forçada contra autoridades administrativas (Lei 5.868/1973, Código de Processo Civil, artigo 730 e seguintes), salvo para créditos de pequeno valor (Lei 10.259/2001, artigo 17, parágrafo 2; e Lei 12.153/2009, artigo 13 , parágrafo $1^{\circ}$ ). No entanto, a jurisprudência recentemente vem autorizando, em casos de excepcional urgência, a execução forçada de créditos de qualquer valor (BRASIL. Supremo Tribunal Federal. STA 36-8. Relator Min. Nelson Jobim. Publicado em: 27 set. 2005. Disponível em: <www.stf.jus.br>. Acesso em: 18 jun. 2013). Sobre este aspecto, ver SUPREMO TRIBUNAL FEDERAL. Sequestro de verbas públicas em favor de doente grave é tema de repercussão geral. Notícias STF, 19 nov. 2012. Disponível em: <http://www.stf. jus.br/portal/cms/verNoticiaDetalhe.asp?idConteudo=224106>. Acesso em: 15 out. 2013.'

${ }^{66}$ PERLINGEIRO, Ricardo. Execução contra a Fazenda Pública. São Paulo: Malheiros Ed., 1999. p. 217-226.
} 
público apenas nas seguintes circunstâncias: (a) bens públicos dominicais, como as terras devolutas, ou bens públicos não afetados em geral, como os recursos financeiros fruto de arrecadação tributária ${ }^{66}$; (b) bens e recursos financeiros afetados a serviço público não essencial, acessório e tipicamente privado, como as despesas destinadas a propaganda governamental na mídia ou a compra de carros oficiais luxu$\operatorname{osos}^{67}$; e (c) bens e recursos destinados ao pagamento de dívidas pretéritas, enquanto, per si, não forem capazes de obstar a continuidade de um serviço público essencial.

Portanto, antes de se preocupar com a exigibilidade e justiciabilidade dos direitos aos cuidados de saúde, e antes de se preocupar com a existência de recursos orçamentários e com uma eficaz gestão pública na área da saúde, é necessário buscar uma compreensão dos efeitos da realidade econômica junto às autoridades públicas quanto aos recursos financeiros que orientam o alcance do direito a um mínimo existencial, em face do qual toda a ordem jurídica tende a acomodar-se e os conflitos reduzirem-se.

Nesse contexto, uma pergunta é especialmente pertinente: Qual o alcance da expressão mínimo existencial quanto a cuidados de saúde a idosos ${ }^{68}$ ?

\section{O mínimo existencial referente a aspectos procedimentais do direito à saúde}

Como antes mencionado, a definição de um mínimo existencial reclama não somente considerações objetivas, mas principalmente subjetivas quanto a aspectos subjetivos do indivíduo e da comunidade em que este se insere ${ }^{69}$. No presente estudo, limitar-me-ei a fatores objetivos do direito a um mínimo existencial.

Em um primeiro momento, tratarei do direito a um mínimo existencial em matéria de saúde à luz dos direitos procedimentais, os que dizem respeito às políticas de saúde essenciais; posteriormente, o mínimo existencial será examinado sob a perspectiva dos direitos substantivos, isto é, associado aos medicamentos, serviços e produtos de saúde essenciais.

Quanto às políticas públicas,

O direito à saúde está intimamente relacionado com o exercício de outros direitos humanos e depende destes direitos, que são enunciados na Carta Internacional dos Direitos Humanos, em

\footnotetext{
${ }^{67}$ Ver em geral: JUIZ suspende publicidade oficial e concede dinheiro à saúde. Conversa Afiada, 31 jul. 2013. Disponível em: <http://www.conversaafiada.com.br/pig/2013/07/31/juiz-suspende-publicidade-oficial-eda-dinheiro-a-saude/>. Acesso em: 15 out. 2013; MPF/RR pede sequestro e bloqueio das contas do Estado de Roraima caso ordem judicial seja descumprida. Procuradoria da República em Roraima, 4 abr. 2013. Disponível em: <http://www.prrr.mpf.mp.br/noticias/04-04-13-mpf-rr-pede-sequestro-e-bloqueio-das-contas-do-estado-de-roraima-caso-nao-seja-comprovado-o-cumprimento-de-ordem-judicial/>. Acesso em: 15 out. 2013.68Sobre um mínimo existencial em matéria de saúde, ver BARCELLOS, Ana Paula de. op. cit.

${ }^{69}$ Jordi Bonet Pérez se refere a mínimo material e mínimo pessoal (BONET PÉREZ, Jordi. Dret internacional dels drets humans en períodes de crisi: criteris d'aplicació de les obligacions jurídiques internacionals en matèria de drets econòmics, socials i culturals. Revista Catalana de Dret Públic, Catalunya, n. 46, p. 14-46, 2013).
} 
particular o direito à alimentação, à habitação, ao trabalho, à educação, à dignidade da pessoa humana, à vida, à não discriminação, à igualdade, a não ser submetido a torturas, à vida privada, ao acesso à informação e à liberdade de associação, reunião e circulação. Estes e outros direitos e liberdades tratam dos componentes integrais do direito à saúde ${ }^{70}$.

\section{Como lembra o Comitê de Direitos Econômicos, Sociais e Culturais ${ }^{71}$ :}

Assim como todos os direitos humanos, o direito à saúde impõe três níveis de obrigações aos Estados Partes: a obrigação de respeitar, proteger e cumprir. Por sua vez, a obrigação de cumprir compreende a obrigação de facilitar, proporcionar e promover. A obrigação de respeitar exige que os Estados abstenham-se de interferir direta ou indiretamente no gozo do direito à saúde. A obrigação de proteger exige que os Estados adotem medidas para impedir que terceiros interfiram na aplicação das garantias previstas no artigo 12. Por fim, a obrigação de cumprir exige que os Estados adotem medidas apropriadas de carácter legislativo, administrativo, orçamentário, judicial ou de outra natureza para conferir plena efetividade ao direito à saúde ${ }^{72}$. (grifos do autor)

\section{É sabido que o}

Direito à saúde não significa direito de gozar de boa saúde, muito menos que os governos de países pobres tenham que estabelecer serviços de saúde caros para aqueles que não dispõem de recursos. Significa que os governos e as autoridades públicas devem estabelecer políticas e planos de ação com o objetivo de que todas as pessoas tenham acesso à atenção de saúde em um prazo mais breve possível. Conseguir que isso ocorra é o desafio daqueles que lidam tanto com a comunidade responsável pela proteção dos direitos humanos como dos profissionais de saúde pública ${ }^{73}$.

\footnotetext{
${ }^{70}$ ORGANIZAÇÃO DAS NAÇÕES UNIDAS (ONU). Comitê de Direitos Econômicos, Sociais e Culturais. General comment 14: the right to the highest attainable standard of health (article 12 of the International Covenant on Economic, Social and Cultural Rights), cit.

${ }^{71} \mathrm{~A}$ partir de maio de 2013 , o Comitê passa a ter competência para receber e apreciar comunicações a que se refere o Protocolo Facultativo ao Pacto Internacional sobre os Direitos Econômicos, Sociais e Culturais. O referido Protocolo foi adotado pela Assembleia Geral das Nações Unidas de 10 de dezembro de 2008, através da resolução A/RES/63/117; aberto à assinatura em 24 de setembro de 2009, em Nova lorque, tendo entrado em vigor em 05 de maio de 2013. ORGANIZAÇÃO DAS NAÇÕES UNIDAS (ONU). Protocolo Facultativo ao Pacto Internacional sobre os Direitos Económicos, Sociais e Culturais. Gabinete de Documentação e Direito Comparado. Disponível em: <http://direitoshumanos.gddc.pt/3_1/IIIPAG3_1_5.htm>. Acesso em: 14 out. 2013.720RGANIZAÇÃO DAS NAÇÕES UNIDAS (ONU). Comitê de Direitos Econômicos, Sociais e Culturais. General comment 14: the right to the highest attainable standard of health (article 12 of the International Covenant on Economic, Social and Cultural Rights), cit.

${ }^{73}$ ROBINSON, Mary. El derecho a la salud. Boletín Derechos humanos, Guatemala, n. 19. Disponível em: <http://www.ohchr.org.gt/documentos/boletines/boletin_19.pdf>. Acesso em: 21 out. 2013.
} 
Porém, como é possível impor aos países pobres com recursos limitados as mesmas normas em matéria de direitos humanos impostas aos países ricos ${ }^{74}$ ?

As medidas destinadas a obter a plena realização dos direitos devem ser deliberadas, concretas e orientadas o mais claramente possível até o cumprimento das obrigações que cabem aos governos. Nesse sentido, é preciso utilizar todos os meios oportunos, em particular adotar disposições legislativas, oferecer recursos judiciais e medidas administrativas, financeiras, educativas e sociais. Isso não exige nem exclui que qualquer tipo específico de governo ou de sistema econômico possa ser utilizado como um meio para a adoção das medidas em questão.

O princípio da realização progressiva dos direitos humanos impõe a obrigação de trabalhar de modo mais diligente e eficaz possível para alcançar esse objetivo. Consequentemente, é aplicado tanto aos países mais pobres como aos mais ricos, na medida em que reconhecem as limitações relacionadas com os recursos disponíveis, mas exige que todos os países tentem fazer progressos de forma constante com o objetivo de alcançar a plena efetividade dos direitos pertinentes. Todas as medidas deliberadas que constituam um passo atrás deverão ser cuidadosamente consideradas e justificadas plenamente em relação aos direitos previstos no tratado de direitos humanos em questão e no contexto da utilização plena do máximo dos recursos disponíveis. Referente a essa questão, é importante distinguir se um Estado-Parte não pode ou não deseja cumprir suas obrigações. Durante o processo relativo à apresentação de relatórios, os Estados-Partes e o Comitê estabelecem indicadores e pontos de referência nacionais para determinar objetivos realistas para o período seguinte sobre o qual deverão informar ${ }^{75}$.

Próximo à noção de proporcionalidade, necessária para delimitar um mínimo existencial, o Comitê de Direitos Econômicos, Sociais e Culturais destaca que:

As medidas viáveis mais apropriadas para o exercício do direito à saúde variaram significativamente de um Estado para outro. Cada Estado tem uma margem de discrição para determinar quais medidas são as mais convenientes para tratar suas circunstâncias específicas. Não obstante, o Pacto impõe claramente a cada Estado a obrigação de adotar as medidas que sejam necessárias para que todos tenham acesso aos estabelecimentos, bens e serviços de saúde e possam gozar quanto antes do mais alto nível

\footnotetext{
${ }^{74}$ ORGANIZAÇÃO DAS NAÇÕES UNIDAS (ONU). Veinticinco preguntas y respuestas sobre salud y derechos humanos. Serie de publicaciones sobre salud y derechos humanos, Paris, n. 1, 2002, p. 14. Disponível em: <http://whqlibdoc.who.int/publications/2002/9243545698_spa.pdf>. Acesso em: 15 out. 2013.

${ }^{75}$ Id. Ibid.
} 
possível de saúde física e mental. Para isso é necessário adotar uma estratégia nacional que permita a todos gozar do direito à saúde, baseado nos princípios de direitos humanos que definem os objetivos dessa estratégia, e formular políticas e estabelecer os indicadores e as bases de referência correspondentes do direito à saúde. A estratégia nacional em matéria de saúde também deverá levar em consideração os recursos disponíveis para alcançar os objetivos determinados, bem como o modo mais proveitoso de utilizar esses recursos ${ }^{76}$.

Dessa forma, conforme o Comitê, o direito à saúde em todas as suas formas e em todos os níveis inclui os seguintes elementos essenciais e inter-relacionados, cuja aplicação dependerá das condições prevalentes em um determinado Estado-Parte:

(a) Disponibilidade. Cada Estado-Parte deve contar com um número suficiente de estabelecimentos, bens e serviços públicos de saúde e centros de atenção à saúde, bem como de programas. A natureza precisa dos estabelecimentos, bens e serviços dependerá de diversos fatores, em particular do nível de desenvolvimento do Estado Parte. Ainda, esses serviços incluirão os fatores determinantes básicos da saúde, como água limpa potável e condições sanitárias adequadas, hospitais, clínicas e demais estabelecimentos relacionados à saúde, pessoal médico e profissionais capacitados e bem remunerados, conforme as condições existentes no país, bem como os medicamentos essenciais definidos no Programa de Ação sobre medicamentos essenciais da OMS.

(b) Acessibilidade. Os estabelecimentos, bens e serviços de saúde devem ser acessíveis a todos, sem qualquer discriminação, dentro da jurisdição do Estado-Parte. A acessibilidade apresenta quatro dimensões sobrepostas: (i) Não discriminação: os estabelecimentos, bens e serviços de saúde devem ser acessíveis, de fato e de direito, aos setores mais vulneráveis e marginalizados da população, sem qualquer discriminação por qualquer um dos motivos proibidos. (ii) Acessibilidade física: os estabelecimentos, bens e serviços de saúde devem estar ao alcance geográfico de todos os setores da população, principalmente aos grupos vulneráveis ou marginalizados, como as minorias étnicas e populações indígenas, mulheres, crianças, adolescentes, idosos, portadores de deficiências e os portadores de VIH/SIDA. A acessibilidade também implica que os serviços médicos e os fatores determinantes básicos de saúde, como água limpa potável e os serviços sanitários adequados, encontrem-se em uma distância geográfica razoável, inclusive no

\footnotetext{
${ }^{76}$ ORGANIZAÇÃO DAS NAÇÕES UNIDAS (ONU). Comitê de Direitos Econômicos, Sociais e Culturais. General comment 14: the right to the highest attainable standard of health (article 12 of the International Covenant on Economic, Social and Cultural Rights), cit.
} 
que se refere às zonas rurais. Além disso, a acessibilidade compreende o acesso adequado aos edifícios pelos portadores de deficiências. (iii) Acessibilidade econômica (acessibilidade de preços): os estabelecimentos, bens e serviços de saúde devem estar ao alcance de todos. O pagamento de serviços de atenção à saúde e serviços relacionados com os fatores determinantes básicos deve basear-se no princípio da equidade, para garantir que esses serviços, públicos ou privados, estejam ao alcance de todos, incluindo os grupos socialmente desfavorecidos. A equidade exige que sobre os lares mais pobres não recaia uma carga desproporcional, referente aos gastos de saúde, em comparação com os lares mais ricos. (iv) Acesso à informação: esse acesso compreende o direito de solicitar, receber e difundir informações e ideias sobre as questões relacionadas à saúde. Ainda, o acesso à informação não deve desprezar o direito de que os dados pessoais relacionados à saúde sejam tratados com confidencialidade. (c) Aceitabilidade. Todos os estabelecimentos, bens e serviços de saúde devem respeitar a ética médica e devem ser culturalmente apropriados, ou seja, respeitar a cultura das pessoas, minorias, povos e comunidades, e ao mesmo tempo sensíveis a todos os requisitos de gênero e ciclo de vida, e devem ser concebidos para respeitar a confidencialidade e melhorar o estado de saúde das pessoas envolvidas. (d) Qualidade. Além da aceitabilidade do ponto de vista cultural, os estabelecimentos, bens e serviços de saúde devem ser ainda apropriados do ponto de vista científico e médico e de boa qualidade. Isso requer, entre outras coisas, pessoal médico capacitado, medicamentos e equipamentos hospitalares cientificamente aprovados e em bom estado, água limpa potável e condições sanitárias adequadas ${ }^{77}$.

$\mathrm{Na}$ Observação Geral $n^{\circ}$ 3, o Comitê confirma que os Estados-Partes têm a obrigação fundamental de garantir níveis essenciais mínimos de satisfação de cada um dos direitos enunciados no Pacto, incluindo a atenção primária básica da saúde. Considerada em conjunto com instrumentos mais recentes, como o Programa de Ação da Conferência Internacional sobre População e Desenvolvimento, a Declaração de Alma-Ata oferece uma orientação inequívoca em relação às obrigações básicas decorrentes do artigo 12. Assim, o Comitê considera que entre essas obrigações básicas figuram, como mínimo, as seguintes ${ }^{78}$ :

\footnotetext{
${ }^{77}$ ORGANIZAÇÃO DAS NAÇÕES UNIDAS (ONU). Comitê de Direitos Econômicos, Sociais e Culturais. General comment 14: the right to the highest attainable standard of health (article 12 of the International Covenant on Economic, Social and Cultural Rights), cit.

${ }^{78}$ Id. Ibid. Ver também GROVER, Anand. Thematic study on the realization of the right to health of older persons by the Special Rapporteur on the right of everyone to the enjoyment of the highest attainable standard of physical and mental health. In: Human Rights Council. $18^{a}$ Sessão. Agenda item 3. Promotion and protection of all human rights, civil, political, economic, social and cultural rights, including the right to development. 4 jul. 2011. Disponível em: <http://www2.ohchr.org/english/bodies/hrcouncil/docs/18session/A-HRC-18-37_en.pdf>. Acesso em: 11 out. 2013.
} 
(a) Garantir o direito de acesso aos centros, bens e serviços de saúde em uma base não discriminatória, principalmente em relação aos grupos vulneráveis ou marginalizados.

$[\ldots]^{79}$

(e) Assegurar uma distribuição equitativa de todas as instalações, bens e serviços de saúde.

(f) Adotar e aplicar, com base em dados epidemiológicos, uma estratégia e um plano de ação nacional de saúde pública para enfrentar as preocupações em matéria de saúde de toda população; a estratégia e o plano de ação devem ser elaborados, e periodicamente revisados, com base em um processo participativo e transparente; essa estratégia e esse plano devem prever métodos, como o direito aos indicadores e bases de referência de saúde que permitam observar de perto os progressos; o processo mediante o qual são concebidos a estratégia e o plano de ação, bem como o conteúdo de ambos, deve prestar atenção especial a todos os grupos vulneráveis ou marginalizados.

\section{O mínimo existencial referente a aspectos substantivos do direito à saúde}

A respeito dos direitos substantivos, como os medicamentos, serviços e produtos de saúde essenciais:

O fato de que o direito à saúde deve ser um objetivo programático tangível não significa que nenhuma obrigação imediata nos Estados surja a partir deste. De fato, os Estados devem realizar todos os esforços possíveis, com os recursos disponíveis, para realizar o direito à saúde e tomar medidas nessa direção sem qualquer demora. Não obstante as restrições de recursos, algumas obrigações têm um efeito imediato, como o comprometimento para garantir o direito à saúde de um modo não discriminatório, o desenvolvimento de legislação específica e plano de ação, ou outras medidas semelhantes para a realização total desse direito, assim como ocorre com qualquer outro direito humano. Os Estados devem ainda garantir um nível mínimo de acesso aos componentes materiais essenciais do direito à saúde, como o fornecimento de medicamentos essenciais e serviços de saúde materno e infantil ${ }^{80}$.

\footnotetext{
${ }^{79}$ (b) To ensure access to the minimum essential food which is nutritionally adequate and safe, to ensure freedom from hunger to everyone; (c) To ensure access to basic shelter, housing and sanitation, and an adequate supply of safe and potable water; (d) To provide essential drugs, as from time to time defined under the WHO Action Programme on Essential Drugs.

${ }^{80}$ ORGANIZAÇÃO DAS NAÇÕES UNIDAS (ONU). The Right to Health. Fact Sheet, n. 32, cit.
} 
A Conferência de Alma-Ata de 1978 sobre cuidados primários de saúde reconheceu que os medicamentos essenciais são vitais para a prevenção e tratamento de enfermidades que afetam milhões de pessoas em todo o mundo. Os medicamentos essenciais salvam vidas e promovem a saúde.

Em 1981, a OMS estabeleceu o Programa de Ação de Medicamentos Essenciais para apoiar os países na implementação de suas políticas nacionais de medicamentos e para trabalhar com o uso racional destes. Esse trabalho foi ampliado em 1998 quando a organização criou o departamento de Medicamentos Essenciais e Outros Medicamentos (EDM), combinando as responsabilidades do antigo DAP com os esforços globais da OMS, para promover a qualidade, a segurança, a eficácia e as informações precisas sobre todos os medicamentos ${ }^{81}$.

Com efeito, a dificuldade de colocar isso em prática é refletida na definição um pouco maior e mais categórica de 2002:

São considerados medicamentos essenciais os que atendem as necessidades de atenção de saúde prioritárias da população. A seleção é feita considerando-se a prevalência das enfermidades e sua segurança, eficácia e relação custo-eficácia comparativa ${ }^{82}$.

Pretende-se que os medicamentos essenciais estejam sempre disponíveis dentro do contexto de funcionamento dos sistemas de saúde em quantidades adequadas, nas formas de dosagem apropriadas, com qualidade garantida e informações apropriadas, e com um preço que o indivíduo e a comunidade possam pagar. A implementação do conceito de medicamentos essenciais pretende ser flexível e adaptável às muitas situações diferentes; definir precisamente quais medicamentos são considerados essenciais permanece como uma responsabilidade nacional ${ }^{83}$.

O Comentário Geral do Comitê de Direitos Econômicos, Sociais e Culturais, de 14 de maio de 2000, é particularmente relevante para o acesso aos medicamentos essenciais. Aqui o Comitê declara que o direito aos serviços médicos no artigo 12.2(d) do PIDESC inclui o fornecimento de medicamentos essenciais "conforme definido pelo Programa de Ação de Medicamentos Essenciais da OMS”. De acordo com a última definição da OMS, medicamentos essenciais são

\footnotetext{
${ }^{81}$ MÉDICOS SEM FRONTEIRAS. Essential drugs. Practical guidelines intended for physicians, pharmacists, nurses and medical auxiliaries. Fev. 2013. Disponível em: <http://refbooks.msf.org/msf_docs/en/essential_drugs/ed_en.pd>. Acesso em: 11 out. 2013.

${ }^{82}$ ORGANIZAÇÃO DAS NAÇÕES UNIDAS (ONU). Essential medicines. Disponível em: <http://www.who.int/topics/essential_medicines/en/>. Acesso em: 11 out. 2013.

${ }^{83}$ ORGANIZAÇÃO DAS NAÇÕES UNIDAS (ONU). The Selection of Essential Medicines. WHO Policy Perspecties on Medicines, n. 4, jun. 2002. Disponível em: <http://apps.who.int/medicinedocs/en/d/Js2296e/1. html>. Acesso em: 11 out. 2013.
} 
Aqueles que satisfazem as necessidades de cuidados de saúde prioritários da população. Os medicamentos essenciais são selecionados com o devido respeito à prevalência de doenças, evidência de eficácia e segurança e relação custo-eficácia comparativa ${ }^{84}$.

\section{O mínimo existencial quanto a cuidados de saúde a idosos}

De acordo com a Organização Pan-americana da Saúde (OPAS) ${ }^{85}$, em matéria de políticas públicas mínimas à saúde de idosos, deve existir necessariamente um plano de ação sobre a saúde dos idosos incluindo o envelhecimento ativo e saudável que considere: a) saúde dos idosos nas políticas públicas; b) idoneidade dos sistemas de saúde para enfrentar os desafios associados com o envelhecimento da população; c) capacitação dos recursos humanos necessários para enfrentar esse desafio; e d) criação de capacidade destinada a gerar as informações necessárias para realizar e avaliar as ações que melhoram a saúde da população idosa.

Do Plano de Ação Internacional Sobre o Envelhecimento, aprovado na Assembleia Mundial Sobre Envelhecimento (Viena, 1982), destaque-se o seguinte:

[...] Recomendação 10. Será preciso desenvolver na comunidade, na medida do possível, os serviços de saúde e serviços de saúde auxiliares. Esses serviços deverão abranger uma ampla gama de serviços ambulatoriais, tais como centros de cuidado diurnos, clínicas ambulatoriais, hospitais-dia, cuidados médicos e de enfermagem e ajuda domiciliar. Deverão ser oferecidos sempre serviços de urgência. O cuidado em instituições deverá corresponder sempre às necessidades dos idosos. Deverá ser evitado o uso de camas inadequadas nas instalações destinadas aos cuidados da saúde. Em especial, os que não são doentes mentais não deverão ser internados em hospitais psiquiátricos. Devem ser prestados serviços de exame e assessoramento médico em clínicas geriátricas, centros de saúde ou locais da comunidade onde se congreguem pessoas de idade. Deve-se contar com a infraestrutura de saúde necessária, assim como o devido pessoal especializado que possa prestar uma assistência geriátrica integral e completa. No caso de cuidados institucionais, deverá ser evitada a alienação do idoso da sociedade provocada por seu isolamento, buscando, entre outras formas, mais a participação de membros da família e de voluntários.

\footnotetext{
${ }^{84}$ ORGANIZAÇÃO DAS NAÇÕES UNIDAS (ONU). Comitê de Direitos Econômicos, Sociais e Culturais. General comment 14: the right to the highest attainable standard of health (article 12 of the International Covenant on Economic, Social and Cultural Rights), cit.

${ }^{85}$ ORGANIZAÇÃO PANAMERICANA DE SAÚDE. Plan de acción sobre la salud de las personas mayores incluido el envejecimiento activo y saludable. Washington, 28 set. a 2 out. 2009. Disponivel em: <http://www. mayoressaludables.org/plan-de-accion>. Acesso em: 15 out. 2013.
} 
[...] Recomendação 13. Devem ser intensificados os esforços para desenvolver a assistência domiciliar, a fim de prestar serviços de saúde e sociais de alta qualidade na quantidade necessária para que os idosos possam permanecer em suas próprias comunidades e viver na forma mais independente durante o maior tempo possível. $\mathrm{O}$ atendimento domiciliar não deve ser considerado uma alternativa do atendimento institucional, pois ambas se complementam e devem estar vinculadas com o sistema de prestação de serviços de tal modo que as pessoas idosas possam receber os melhores cuidados adequados a suas necessidades, e a um menor custo. Deve-se prestar especial apoio aos serviços de cuidado domiciliar, dotando-os de profissionais médicos, paramédicos, de enfermagem e técnicos suficientes para poder limitar a necessidade de hospitalização ${ }^{86}$.

Peláz e Ferrer propõem, dentre outros indicativos, que haja "um orçamento público e privado para investir em tecnologia de baixo custo e em medicamentos essenciais para o controle das enfermidades comuns nos idosos, e a proibição de discriminação dos idosos em instituições de saúde públicas e privadas"87.

Quanto a medicamentos, serviços e produtos de saúde essenciais à saúde de idosos, recorre-se novamente ao Comitê de Direitos Econômicos, Sociais e Culturais:

No que tange o exercício do direito à saúde dos idosos, o Comitê, conforme disposto nos parágrafos 34 e 35 da observação geral No 6 (1995), reafirma a importância de um enfoque integrado da saúde que inclua a prevenção, a cura e a reabilitação. Essas medidas devem basear-se em avaliações periódicas para ambos os sexos; medidas de reabilitação física e psicológica destinadas a manter a funcionalidade e a autonomia dos idosos; e a prestação de atenção e cuidados aos doentes crônicos e em estado terminal, poupando-os de dores evitáveis e permitindo que morram com dignidade ${ }^{88}$. (grifos do autor).

Com efeito, os direitos substantivos aos cuidados de saúde dos idosos estão relacionados com medicamentos, serviços e produtos essenciais a enfermidades em geral que se manifestam com mais frequência a partir de determinada idade, cuidados primários e enfermidades crônicas, cuidados paliativos e enfermidades inerentes à própria idade avançada, como o mal de Alzheimer.

\footnotetext{
${ }^{86}$ ORGANIZAÇÃO DAS NAÇÕES UNIDAS (ONU). Vienna International Plan of Action on Aging. Viena, 1982. Disponivel em: <http://www.un.org/es/globalissues/ageing/docs/vipaa.pdf>. Acesso em: 15 out. 2013. ${ }^{87}$ PELÁEZ, Martha B; FERRER LUES, Marcela. op. cit.

${ }^{8}$ ORGANIZAÇÃO DAS NAÇÕES UNIDAS (ONU). Comitê de Direitos Econômicos, Sociais e Culturais. General comment 14: the right to the highest attainable standard of health (article 12 of the International Covenant on Economic, Social and Cultural Rights), cit.
} 
No Brasil, a Política Nacional de Saúde da Pessoa Idosa foi aprovada em 2006, pelo Ministério da Saúde ${ }^{89}$, também valendo referência o Plano de Saúde Suplementar para Idosos, adotado no Brasil em $2012^{90}$. Do ponto de vista dos direitos substantivos, as prestações (medicamentos, produtos e serviços) básicas sobre cuidados de saúde inerentes a idosos são ofertadas pelo Sistema Único de Saúde (SUS) ${ }^{91}$, tendo como principal parâmetro a idade do paciente, acima de 60 anos. Os medicamentos, produtos e serviços essenciais a toda a população são, naturalmente, de forma igual, considerados essenciais à população idosa. Não obstante, em particular, vale mencionar que o SUS assegura o tratamento para a doença de Alzheimer ${ }^{92}$ e a osteoporose, ${ }^{93}$ e disponibiliza parcialmente fraldas geriátricas ${ }^{94}$.

${ }^{89}$ BRASIL. Ministério da Saúde. Portaria oo 2.528 de 19 de outubro de 2006. Disponível em: <http://dtr2001. saude.gov.br/sas/PORTARIAS/Port2006/GM/GM-2528.htm>. Acesso em: 9 jan. 2014.

${ }^{9}$ AGÊNCIA NACIONAL DE SAÚDE SUPLEMENTAR (ANS). Plano de Cuidado para Idosos na Saúde Suplementar. Rio de Janeiro: ANS, 2012. Disponível em: <http://bvsms.saude.gov.br/bvs/publicacoes/plano_cuidado_idosos.pdf>. Acesso em: 9 jan. 2014.

91“Nos Estados Unidos, o Medicare (programa de financiamento público) oferece cobertura para cerca de 40 milhões de americanos idosos e deficientes. O Medicare Parte A cobre a maioria dos americanos com mais de 65 anos, e oferece cobertura de seguro de hospital. Embora o Medicare Parte B seja opcional, quase todas as partes elegiveis se inscrevem, dados os substanciais subsídios federais para o programa. O Medicare Part $\mathrm{B}$ oferece cobertura médica suplementar para, entre outras coisas, consultas médicas e exames de diagnóstico. Muitos beneficiários do Medicare também adquirem o seguro suplementar Medicare (Medigap) ou contam com a cobertura de um ex-empregador. As políticas do Medigap são regulamentadas em nível federal e devem incluir benefícios básicos especificados". (THE UNITED STATES. Department of Justice. Executive summary. Disponivel em: <http://www.justice.gov/atr/public/health_care/204694/exec_sum.htm>. Acesso em: 16 out. 2013 e <http://www.hhs.gov/ocio/about/whatwedo/what.html>. Acesso em: 9 jun. 2014). No Reino Unido, existem diversos serviços prestados pelo NHS a idosos, tais como: emergencial, que ocorre normalmente nos hospitais, de atendimento médico (GP) e dentistas, entre outros. Todos eles podem ou não envolver custos para os pacientes. (GUIDE to social care services.Disponível em: <http://www.nhs.uk/ NHSEngland/AboutNHSservices/social-care-services/Pages/social-care-adults.aspx>. Acesso em: 16 out. 2013). Em Portugal, a prestação de saúde é oferecida pelo Serviço Nacional de Saúde (SNS), no qual o reconhecimento do direito ao complemento solidário para idosos depende de o requerente satisfazer, cumulativamente, as condições legais previstas (BENEFícIOS adicionais de saúde para idosos. Portal da Saúde. Disponível em: <http://www.portaldasaude.pt/portal/conteudos/informacoes+uteis/comparticipacoes/beneficios+adicionais+saude+idosos.htm>. Acesso em: 16 out. 2013).

${ }^{92}$ Os medicamentos e serviços para a doença de Alzheimer são disponibilizados por meio do Componente Especializado da Assistência Farmacêutica (CEAF - Portaria MS/GM 2.981, de 26 de novembro de 2009), sendo padronizados os seguintes medicamentos: Donepezila $5 \mathrm{mg}$ e $10 \mathrm{mg}$; Galantamina $8 \mathrm{mg}, 16 \mathrm{mg}$ e 24 mg; Rivastigmina 2 mg/mL e Rivastigmina 1,5 mg, 3 mg, 4,5 mg e 6 mg. Dessa forma, no CEAF, são disponibilizados medicamentos da classe farmacológica importante para o manejo da doença de Alzheimer a todos os pacientes que apresentam os critérios de inclusão estabelecidos pelo Protocolo Clínico e Diretrizes Terapêuticas (PCDT - DOENÇA DE ALZHEIMER, Portaria SAS/MS 843, de 31 de outubro de 2002).

${ }^{93} \mathrm{O}$ tratamento para osteoporose é oferecido por meio do CEAF. O SUS garante o tratamento efetivo para os pacientes que se enquadrarem no PCDT para esta doença (Portaria SAS/MS 470, de 23 de Julho de 2002), tendo acesso aos seguintes medicamentos: Pamidronato 30 mg injetável, Pamidronato 60 mg injetável, Risedronato $5 \mathrm{mg} / \mathrm{cp}$, Risedronato $35 \mathrm{mg} / \mathrm{cp}$, Raloxifeno $60 \mathrm{mg} / \mathrm{cp}$, Calcitonina 50 Ul injetável, Calcitonina $100 \mathrm{UI}$ injetável, Calcitonina $200 \mathrm{UI}$ spray nasal, Calcitriol 0,25 mcg/cp, Alendronato $10 \mathrm{mg} / \mathrm{cp}$ (Componente Básico da Assistência Farmacêutica), Alendronato $70 \mathrm{mg} / \mathrm{cp}$ (Componente Básico da Assistência Farmacêutica). Lembramos que a execução do Componente, que envolve as etapas de solicitação, avaliação, autorização e renovação da continuidade de tratamento, é responsabilidade das secretarias estaduais de saúde.

${ }^{94} \mathrm{As}$ fraldas geriátricas têm sido objeto do maior número de demandas judicais, apesar do Programa Farmácia Popular oferecê-las para pessoas idosas, mediante prescrições, laudos ou atestados médicos, subsidiando o Ministério da Saúde o pagamento de $90 \%$ do custo; a população contribui com 10\% desse valor. 


\section{Considerações finais}

Os cuidados de saúde a idosos são direitos fundamentais sociais, e o seu núcleo essencial, vinculado aos princípios da dignidade humana e do direito à vida, é também conhecido como mínimo existencial.

O direito a um mínimo existencial é exigível automaticamente perante as autoridades públicas (legislativa e administrativa), tanto sob o prisma dos direitos procedimentais quanto dos direitos substantivos.

As dificuldades orçamentárias e financeiras do poder público não são extintivas dos direitos aos cuidados de saúde, e não esvaziam sua exigibilidade e justiciabilidade. No entanto, esses embaraços econômicos podem, no caso concreto, obstar ou limitar o exercício dos direitos de saúde, e também impedir o surgimento deles, à medida que influenciarem os contornos do que se entende por mínimo existencial.

De fato, a delimitação do mínimo existencial em matéria de cuidados de saúde depende da ponderação proporcional entre fatores objetivos, como os medicamentos, serviços e produtos de saúde essenciais, e fatores subjetivos, como a necessidade concreta dos indivíduos, o nível de desenvolvimento social e das condições de vida existentes, e as disponibilidades financeiras do poder público.

Os indicadores objetivos dos cuidados de saúde, considerados essenciais no âmbito da aplicação de normas internacionais de direitos humanos, têm primazia e consistem no patamar inicial de um mínimo existencial, a partir do qual a ordem jurídica nacional detém uma margem de discricionariedade, de acordo com parâmetros subjetivos (necessidades individuais e aspectos socioeconômicos). De um lado, essa discricionariedade atua para aumentar o alcance dos direitos sociais, porém, de outro lado, fundado na mesma subjetividade, ela atua para restringi-los, mas, neste caso, desde que justificadamente.

Os aspectos objetivos a serem considerados em um mínimo existencial sobre cuidados de saúde e em especial a idosos são os que mantêm uma estreita vinculação com a idade do indivíduo.

Sob o ponto de vista dos direitos procedimentais, consideram-se essenciais: a inclusão da saúde dos idosos nas políticas públicas; a capacitação de recursos humanos especializados; a proibição de qualquer discriminação em função da idade; a existência de centros de cuidado diurno, clínicas ambulatoriais, hospitais-dia; o atendimento em clínicas geriátricas onde se congreguem idosos; e a assistência domiciliar, limitando a necessidade de hospitalização.

No âmbito dos direitos substantivos, são essenciais aos cuidados de idosos: check-ups periódicos; reabilitação física e psicológica, destinada à funcionalidade e autonomia dos idosos; e atenção e cuidados a enfermidades crônicas e em fase terminal. 


\section{Referências}

ABRAHAM, Marcus. Direito é ferramenta fundamental de transformação social. Consultor Jurídico, São Paulo, 4 jul. 2013. Disponível em: <http://www.conjur.com.br/2013-jul-03/marcusabraham-direito-ferramenta-fundamental-trasformacao-social\#autores $>$. Acesso em: 18 jul. 2013.

AGÊNCIA NACIONAL DE SAÚDE SUPLEMENTAR (ANS). Plano de Cuidado para Idosos na Saúde Suplementar. Rio de Janeiro: ANS, 2012. Disponível em: <http://bvsms.saude.gov. br/bvs/publicacoes/plano_cuidado_idosos.pdf>. Acesso em: 9 jan. 2014.

ALEMANHA. Tribunal Constitucional Federal (BVerfG). 1 BvL 1/09 - 1 BvL 3/09 - 1 BvL 4/09. j. 9 fev. 2010. Disponível em: <http://www.bundesverfassungsgericht.de/entscheidungen/ ls20100209_1bvl000109.html>. Acesso em: 23 abr. 2013.

. Tribunal Constitucional Federal (BVerfG). 1 BvR 347/98, Absatz-Nr. (1 - 69). j. 6 dez. 2005. Disponível em: <http://www.bverfg.de/entscheidungen/rs20051206_1bvr034798. html>. Acesso em: 17 jan. 2013.

ALEXY, Robert. Teoria dos direitos fundamentais. Tradução de Virgílio Afonso da Silva. São Paulo: Malheiros Ed., 2008.

BARCELLOS, Ana Paula de. A construção de um mínimo existencial em matéria de prestações de saúde. In: SOUZA NETO, Cláudio Pereira; SARMENTO, Daniel (Orgs.). Direitos sociais: fundamentos, judicialização e direitos sociais em espécie. Rio de Janeiro: Lumen Juris, 2008.

BARNES, Javier. Tres generaciones de procedimiento administrativo. In: ABERASTURY, Pedro; BLANKE, Hermann-Josef (Orgs.). Tendencias actuales del procedimiento administrativo en Latinoamérica y Europa. Buenos Aires: Fundación Konrad Adenauer, 2012. p. 119-164.

BENEFÍCIOS adicionais de saúde para idosos. Portal da Saúde. Disponível em: <http://www. portaldasaude.pt/portal/conteudos/informacoes+uteis/comparticipacoes/beneficios+adicio nais+saude+idosos.htm>. Acesso em: 16 out. 2013.

BONET PÉREZ, Jordi. Dret internacional dels drets humans en períodes de crisi: criteris d'aplicació de les obligacions jurídiques internacionals en matèria de drets econòmics, socials i culturals. Revista Catalana de Dret Públic, Catalunya, n. 46, p. 14-46, 2013.

BRASIL. Supremo Tribunal Federal. Plenário. Repercussão Geral no Recurso Extraordinário 631.240/ MG. Rel. Min. Joaquim Barbosa. Disponível em: <www.stf.jus.br>. Acesso em: 18 jun. 2013.

. Supremo Tribunal Federal. Sequestro de verbas públicas em favor de doente grave é tema de repercussão geral (Notícias STF, 19 nov. 2012. Disponível em: <http://www.stf. jus.br/portal/cms/verNoticiaDetalhe.asp?idConteudo=224106>. Acesso em: 15 out. 2013.

. Supremo Tribunal Federal. STA 36-8. Relator Min. Nelson Jobim. Publicado em: 27 set. 2005. Disponível em: <www.stf.jus.br>. Acesso em: 18 jun. 2013.

BREWER-CARÍAS, Allan R. Principios del procedimento administrativo en América Latina. Bogotá: LEGIS, 2003. 
CANAL Saúde. Disponível em: <http://www.canal.fiocruz.br/destaque/index.php?id=859>. Acesso em: 11 out. 2013.

CILIONE, Giampiero. Diritto sanitario. Santarcangelo di Romagna: Maggioli Editore, 2005. CONFERÊNCIA INTERNACIONAL AMERICANA, IX, 1948, Bogotá. Declaração Americana dos Direitos e Deveres do Homem. Bogotá, OEA, 1948. Disponível em: <http://www.cidh.oas. org/basicos/portugues/b.Declaracao_Americana.htm>. Acesso em: 11 out. 2013.

CONGRÈS DE L'ASSOCIATION INTERNATIONALE DES HAUTES JURIDICTIONS ADMINISTRATIVES, 8, 2004, Madrid. L'exécution des decisions des jurisdictions administratives. Disponível em: $<$ http://www.aihja.org/images/users/1/files/2004_Congres_ de_Madrid_Rapport_VIII_congres_VIII_vf.pdf?PHPSESSID=f83dg63dqj61vokoep4kk44 ful>. Acesso em: 15 out. 2013.

CONSELHO DA EUROPA. Carta Social Europeia. Estrasburgo, 1996. Disponível em: <http:// www.dhnet.org.br/direitos/sip/euro/7.htm>. Acesso em: 11 out. 2013.

EDITORIAL. Manifestação por mais transporte, saúde e educação. Valor Econômico, São Paulo, 19 jun. 2013. Disponível em: <http://www.valor.com.br/politica/3167272>. Acesso em: 11 out. 2013.

EQUALITY AND HUMAN RIGHTS GROUP. Human rigths in healthcare: a short introduction. London: DH Publications Orderline, 2008. Disponível em: <http://www.bihr.org. uk/sites/default/files/Human\%20rights\%20in\%20healthcare\%20-\%20short\%20introduction. pdf $>$. Acesso em: 11 out. 2013.

EUR-LEX. Disponível em: <http://eur-lex.europa.eu/LexUriServ/LexUriServ.do?uri=OJ:C: 2007:303:0001:0016:pt:PDF>. Acesso em: 15 out. 2013.

FALZEA, Angelo. Introduzione alle scienze giurdiiche: il concetto del diritto, 6 ed. Milano: Giuffrè, 2008.

FERCOT, Celine. Le juge et le droit au minimum. Les ambiguïtes du droit à des conditions minimales d'existence en droit comparé. In: ROMAN, Diane (Org.). Droits des pauvres, pauvres droits? Paris: Centre de Recherches sur les droits fondamentaux (CREDOF), Université Paris Ouest Nanterre la Défense, 2010, p. 239-243. Disponível em: <http://www.droitssociaux.u-paris10.fr/assets/files/rapport_final/Justiciabilité_droits_sociaux_rapport_final. pdf $>$. Acesso em: 18 jan. 2013.

FUNDO DAS NAÇÕES UNIDAS PARA A INFÂNCIA (UNICEF). Convenção sobre os Direitos da Criança de 1989. Disponível em: <http://www.unicef.org/brazil/pt/ resources_10120.htm>. Acesso em: 11 out. 2013.

GANDRA, Alana. Mudanças demográficas aumentarão demandas por Previdência Social e Saúde. Agência Brasil, Brasília, 14 ago. 2013. Disponível em: <http://agenciabrasil.ebc.com. br/noticia/2013-08-14/mudancas-demograficas-aumentarao-demandas-por-previdenciasocial-e-saude $>$. Acesso em: 11 out. 2013. 
GORDILLO, Augustín. Tratado de derecho administrativo: el procedimiento administrativo. 7. ed. México: Porruá, 2004. t. 4.

GRECO, Leonardo. Instituições de processo civil. Rio de Janeiro: Forense. 2009. v. 1.

GROVER, Anand. Thematic study on the realization of the right to health of older persons by the Special Rapporteur on the right of everyone to the enjoyment of the highest attainable standard of physical and mental health. In: Human Rights Council. $18^{a}$ Sessão. Agenda item 3. Promotion and protection of all human rights, civil, political, economic, social and cultural rights, including the right to development. 4 jul. 2011. Disponível em: $<$ http://www2.ohchr.org/ english/bodies/hrcouncil/docs/18session/A-HRC-18-37_en.pdf>. Acesso em: 11 out. 2013.

GUIDE to social care services.Disponível em: <http://www.nhs.uk/NHSEngland/ AboutNHSservices/social-care-services/Pages/social-care-adults.aspx>. Acesso em: 16 out. 2013.

HOGERZEIL et al. Is access to essential medicines as part of the fulfilment of the right to health enforceable through the courts? The Lancet, v. 368, p. 305-311, 22 Jul. 2006. Disponível em: <http://www.who.int/medicines/news/Lancet_EssMedHumanRight. pdf $>$. Acesso em: 21 out. 2013.

INSTITUTO BRASILEIRO DE GEOGRAFIA E ESTATÍSTICA. Síntese de Indicadores Sociais. Disponível em: <http://www.ibge.gov.br/home/estatistica/pesquisas/pesquisa_resultados. php?id_pesquisa=47>. Acesso em: 9 jan. 2014.

ISENSSE, J.; KIRCHHOF, P. Handbuch des Staatsrecht, $\$ 99$. Heidelberg, 2007. v. 5.

JUIZ suspende publicidade oficial e concede dinheiro à saúde. Conversa Afiada, 31 jul. 2013. Disponível em: <http://www.conversaafiada.com.br/pig/2013/07/31/juiz-suspendepublicidade-oficial-e-da-dinheiro-a-saude/>. Acesso em: 15 out. 2013.

KIRCHOF, F. Umfassende Staatsgewalt mit begrenzten Mitteln. In: ISENSSE, J.; KIRCHHOF, P. Handbuch des Staatsrecht, \$99. Heidelberg, 2007. v. 5.

MAURER, Hartmut. Derecho administrativo alemán. Cidade do México: UNAM, 2012.

MÉDICOS SEM FRONTEIRAS. Essential drugs. Practical guidelines intended for physicians, pharmacists, nurses and medical auxiliaries. Fev. 2013. Disponível em: <http://refbooks.msf. org/msf_docs/en/essential_drugs/ed_en.pd>. Acesso em: 11 out. 2013.

MENDES, Gilmar Ferreira; COELHO, Inocêncio Mártires; BRANCO, Paulo Gustavo Gonet. Curso de direito constitucional. São Paulo: Saraiva, 2007.

EL MINISTRO de finanzas japonés, Taro Aso, sobre los ancianos: 'Que se den prisa y se mueran”'. 20MINUTOS.ES, Espanha, 22 jan. 2013. Disponível em: <http://www.20minutos. es/noticia/1707874>. Acesso em: 11 out. 2013. 
$\mathrm{MPF} / \mathrm{RR}$ pede sequestro e bloqueio das contas do Estado de Roraima caso ordem judicial seja descumprida. Procuradoria da República em Roraima, 4 abr. 2013. Disponível em: <http:// www.prrr.mpf.mp.br/noticias/04-04-13-mpf-rr-pede-sequestro-e-bloqueio-das-contasdo-estado-de-roraima-caso-nao-seja-comprovado-o-cumprimento-de-ordem-judicial/>. Acesso em: 15 out. 2013.

OEA. Protocolo Adicional à Convenção Americana sobre Direitos Humanos em Matéria de Direitos Econômicos, sociais e culturais - "Protocolo de San Salvador" de 1988. Disponível em: <http://www.cidh.oas.org/basicos/portugues/e.Protocolo_de_San_Salvador.htm>.Acesso em: 15 out. 2013.

ORGANIZAÇÃO DA UNIDADE AFRICANA. Carta Africana de Direitos Humanos e dos Povos. Banjul, 1981. Disponível em: <http://dhnet.org.br/direitos/sip/africa/banjul.htm>. Acesso em: 11 out. 2013.

ORGANIZAÇÃO DAS NAÇÕES UNIDAS (ONU). Alto Comissariado das Nações Unidas para os Direitos Humanos. General comment 6: the economic, social and cultural rights of older persons. Genebra, 1995. Disponível em: <http://www.unhchr.ch/tbs/doc.nsf/0/482a0a ced8049067c12563ed005acf9e>. Acesso em: 11 out. 2013.

Assembleia Geral. Declaração de Cairo sobre os Direitos Humanos no Islã. Cairo, 1993. Disponível em: <http://www.arabhumanrights.org/publications/regional/islamic/ cairo-declaration-islam-93e.pdf>. Acesso em: 15 out. 2013.

Comitê de Direitos Econômicos, Sociais e Culturais. General comment 14: the right to the highest attainable standard of health (article 12 of the International Covenant on Economic, Social and Cultural Rights). Genebra, 2000. Disponível em: <http://www.unhchr.ch/tbs/doc. nsf/(symbol)/E.C.12.2000.4.En>. Acesso em: 11 out. 2013.

Declaração Universal dos Direitos Humanos foi proclamada pela Assembleia Geral das Nações Unidas em Paris, em 10 de Dezembro de 1948, através da Resolução 217 A (III) da Assembleia Geral. Disponível em: <http://unicrio.org.br/img/DeclU_D_ HumanosVersoInternet.pdf $>$. Acesso em: 15 out. 2013.

Essential medicines. Disponível em: <http://www.who.int/topics/essential_medicines/ en/>. Acesso em: 11 out. 2013.

Human rights of older persons: International human rights principles and standards. Disponível em: <http://www.ohchr.org/Documents/Issues/OlderPersons/ OHCHRBackgroudpaper2011.pdf >. Acesso em: 9 jun. 2014.

Pacto Internacional sobre Direitos Econômicos, Sociais e Culturais. Disponível em: <http://treaties.un.org/untc/Pages/ViewDetails.aspx?src=TREATY\&mtdsg_no=IV$3 \&$ chapter=4\&lang=en $\# 2>$. Acesso em: 11 out. 2013. 
. Plano de ação internacional contra o envelhecimento, 2002. Organização das Nações Unidas; tradução de Arlene Santos. Brasília: Secretaria Especial dos Direitos Humanos, 2003. 49 p. (Série Institucional em Direitos Humanos; v. 1). Disponível em: $<$ http://www.saudeidoso. icict.fiocruz.br/pdf/PlanodeAcao\%20Internacionalpara\%20oEnvelhecimentodaONU.pdf > . Acesso em: 9 jan. 2014.

. Protocolo Facultativo ao Pacto Internacional sobre os Direitos Económicos, Sociais e Culturais. Gabinete de Documentação e Direito Comparado. Disponível em: <http:// direitoshumanos.gddc.pt/3_1/IIIPAG3_1_5.htm>. Acesso em: 14 out. 2013.

. The Right to Health. Fact Sheet, n. 32. Disponível em: <http://www.ohchr.org/ Documents/Publications/Factsheet31.pdf >. Acesso em: 11 out. 2013.

. The Selection of Essential Medicines. WHO Policy Perspecties on Medicines, n. 4, jun. 2002. Disponível em: <http://apps.who.int/medicinedocs/en/d/Js2296e/1.html>. Acesso em: 11 out. 2013.

- Veinticinco preguntas y respuestas sobre salud y derechos humanos. Serie de publicaciones sobre salud y derechos humanos, Paris, n. 1, 2002, p. 14. Disponível em: <http:// whqlibdoc.who.int/publications/2002/9243545698_spa.pdf>. Acesso em: 15 out. 2013.

. Vienna International Plan of Action on Aging. Viena, 1982. Disponível em: <http:// www.un.org/es/globalissues/ageing/docs/vipaa.pdf>. Acesso em: 15 out. 2013.

ORGANIZAÇÃO PANAMERICANA DE SAÚDE. Plan de acción sobre la salud de las personas mayores incluido el envejecimiento activo y saludable. Washington, 28 set. a 2 out. 2009. Disponível em: <http://www.mayoressaludables.org/plan-de-accion>. Acesso em: 15 out. 2013.

PASCAL, Elizabeth. Welfare Rights in State Constitutions. New York: Rutgers L.J., 2008, p. 869-870. Disponível em: <http://org.law.rutgers.edu/publications/lawjournal/issues/39_4/0 4PascalVol.39.4.r_1.pdf >. Acesso em: 15 out. 2013.

PELÁEZ, Martha B; FERRER LUES, Marcela. Salud pública y los derechos humanos de los adultos mayores. Acta bioeth, Santiago, v. 7, n. 1, 2001. Disponível em: <http://dx.doi. org/10.4067/S1726-569X2001000100011>. Acesso em: 11 out. 2013.

PERLINGEIRO, Ricardo. Execução contra a Fazenda Pública. São Paulo: Malheiros Ed., 1999.

. É a reserva do possível um limite à intervenção jurisdicional nas políticas públicas sociais? (Does the Proviso of the Possible [Vorbehalt des Möglichen] Limit Judicial Intervention in Social Public Policies?). Revista de Direito Administrativo Contemporâneo REDAC, São Paulo, v. 2, p. 163-185, nov. 2013.

PIEROTH, Bodo; SCHLINK, Bernhard. Direitos fundamentais. São Paulo: Saraiva, 2012.

PORTAL da Saúde. Disponível em: <http://www2.datasus.gov.br/DATASUS/index.php>. Acesso em: 11 out. 2013. 
RIGHETTI, Sabine. Protestos pela saúde pública 'enterra' Dilma e ministros e critica governo. Folha de S. Paulo, São Paulo, 10 out. 2013. Disponível em: <http://www1.folha.uol.com.br/fsp/ cotidiano/119355-protesto-pela-saude-publica-enterra-dilma-e-ministros-e-critica-governo. shtml>. Acesso em: 10 out. 2013.

ROBINSON, Mary. El derecho a la salud. Boletín Derechos humanos, Guatemala, n. 19. Disponível em: <http://www.ohchr.org.gt/documentos/boletines/boletin_19.pdf>. Acesso em: 21 out. 2013.

SILVA, Virgílio Afonso da. Direitos fundamentais. 2. ed. São Paulo: Malheiros Ed., 2011.

SOMMERMANN, Karl-Peter. Soziale Rechte in Stufen: Überwindung einer alten Debatte? In: CALLIESS, Christian; KAHL, Wolfgang; SCHMALENBACH, Kirsten (Orgs.). Rechtsstaatlichkeit, Freiheit und soziale Rechte in der Europäischen Union, 2013.

SOUZA, Mariana Rodrigues Kelly. Princípio da universalidade: efeitos da reforma introduzida pelo Affordable Care Act. Niterói: UFF, 2012.

SUPREMO TRIBUNAL FEDERAL. Sequestro de verbas públicas em favor de doente grave é tema de repercussão geral. Notícias STF, 19 nov. 2012. Disponível em: <http://www.stf. jus.br/portal/cms/verNoticiaDetalhe.asp?idConteudo=224106>. Acesso em: 15 out. 2013.

TORRES, Ricardo Lobo. O direito ao mínimo existencial. Rio de Janeiro: Renovar, 2009.

THE UNITED STATES. Department of Justice. Executive summary. Disponível em: $<$ http:// www.justice.gov/atr/public/health_care/204694/exec_sum.htm>. Acesso em: 16 out. 2013.

UNIVERSIDADE FEDERAL FLUMINENSE, Código modelo de jurisdição administrativa para Euro-América, Niterói, 2010. Texto elaborado durante os três seminários de pesquisa euroamericano euro-americana "Código modelo de jurisdição administrativa”, organizados pelo Grupo de Pesquisa "Efetividade da Jurisdição” na Universidade Federal Fluminense, Niterói, e na Universidade Alemã de Ciências da Administração Pública, Speyer, entre os anos 2008 e 2010, e aprovado no III Seminário que ocorreu em setembro de 2010, em Niterói. Participaram da elaboração: Pedro Aberastury, Hermann-Josef Blanke, Gabriele Bottino, David Capitant, Jesús María Casal, Diana-Urania Galleta, Ricardo Garcia Macho, Leonardo Greco, Lorena Ossio, Gilles Pellissier, Ricardo Perlingeiro e Karl-Peter Sommermann.

WOLF, Hans J.; BACHOF, Otto; STOBER, Rolf. Direito administrativo. Tradução de Antônio F. de Souza. Lisboa: Fundação Calouste Gulbenkian, 2006. v. 1.

Ricardo Perlingeiro - Professor Titular da Faculdade de Direito da Universidade Federal Fluminense. Desembargador Federal do Tribunal Regional Federal da 2a Região. Presidente do Comitê Executivo do Conselho Nacional de Justiça para o monitoramento e resolução das demandas de assistência à saúde no Estado do Rio de Janeiro. Niterói/RJ, Brasil. E-mail: perlingeiro@nupej.uff.br. 